\title{
4. Die antidonatistischen Briefe
}

\section{Die Darstellung der donatistischen Kontroverse}

Die insgesamt 308 überlieferten Briefe der augustinischen Briefsammlung geben einen umfassenden Einblick in das Leben und Wirken Augustins. ${ }^{1}$ In vielen der Briefe wird das donatistische Schisma erwähnt. Darunter befinden sich Schreiben mit kurzen Notizen, Briefe, in denen konkrete Probleme angesprochen werden, aber auch ausführliche Abhandlungen, in denen unterschiedlichste Facetten des Donatismus erörtert werden. ${ }^{2}$ Innerhalb von Augustins Schriften sind die Übergänge zwischen den Gattungen fließend: Einige Briefe tragen deutlich den Charakter eines Traktates oder einer Predigt, umgekehrt finden sich zahlreiche Schriften, die der Form nach den Briefen zuzuordnen sind und trotzdem nicht in der Briefsammlung überliefert wurden. ${ }^{3}$

Von den uns heute erhaltenen Briefen schrieb Augustinus 18 an Donatisten. ${ }^{4}$ Die Adressaten waren zum einen donatistische Bischöfe, darunter $\mathrm{Au}-$ gustins Gegenbischöfe in Hippo Proculeianus (ep. 33) und später Macrobius (epp. 106, 108), ferner Crispinus von Calama (epp. 51, 66), Ianuarianus von Casae Nigrae (ep. 88) sowie Maximinus von Siniti (ep. 23), ein gewisser Honoratus (ep. 49) und Emeritus von Caesarea (ep. 87). Zum anderen schrieb Augustinus an einzelne donatistische Laien (epp. 43, 44, 52, 70), einen Brief an einen donatistischen Priester namens Donatus (ep. 173); drei Briefe richten sich an die Donatisten insgesamt (epp. 76, 105, 141). Eine Sonderrolle nimmt schließlich ep. 93 an Vincentius ein, den Führer der donatistischen Abspaltung der Rogatisten.

1 Edition: S. Aureli Augustini Hipponiensis episcopi epistulae, ed. A. Goldbacher, 4 Bde. Wien 1895-1923 (CSEL 34, 44, 57, 58); Epistulae ex duobus condicibus nuper in lucem prolatae, ed. Johannes Divjak, Wien 1981 (CSEL 88).

2 Ein knapper Überblick über Augustins Briefe im Zusammenhang mit dem Donatismus bei Monceaux VII, 129-146, 279-286. Ergänzend dazu: A. Schindler, Vermitteln die neuentdeckten Augustin-Briefe auch neue Erkenntnisse über die Donatisten?, in: Les Lettres de saint Augustin découvertes par Johannes Divjak, Paris 1983, 117-121. Eine Zusammenstellung aller Briefe mit kurzen Inhaltsangaben bietet F. Morgenstern (Die Briefpartner des Augustinus von Hippo, Bochum 1993), der allerdings Monceaux für die Datierung und inhaltliche Fragen unberücksichtigt lässt. Eine gute, vollständige Übersicht bei J. Divjak, AL 2, 893-1057, s. v. Epistulae.

3 Antidonatistische Traktate innerhalb der Briefsammlung sind ep. 76 und ep. 141; ein Brief außerhalb der Sammlung ist z. B. die Schrift cath. fr. Vgl. Monceaux VII, $142 \mathrm{f}$.

4 Vgl. Morgenstern, Briefpartner, 96-102. 
Während die Schreiben an die donatistischen Laien im Inhalt und Aufbau den antidonatistischen Traktaten und Abhandlungen sehr ähnlich sind, orientiert sich die Thematik der übrigen Briefe an konkreten Problemen, Anfragen oder Vorfällen. ${ }^{5}$ So war beispielsweise der Anlass für Augustins ersten Brief an einen Donatisten (ep. 23) der Bericht über die Wiedertaufe eines katholischen Diakons bei den Donatisten. Gegen die Wiedertaufe wendet er sich auch in den Briefen an Crispinus von Calama und Macrobius. ${ }^{6}$ In der Korrespondenz nach 405 finden sich vermehrt Berichte über donatistische Gewalttaten und Rechtfertigungen des kaiserlichen Eingreifens, so etwa in den Briefen an Ianuarianus (ep. 88) und Vincentius (ep. 93). ${ }^{7}$ Fast durchgängig - insbesondere in den Briefen vor 405 - äußert Augustinus gegenüber seinen donatistischen Briefpartnern den Wunsch, die Differenzen durch Gespräche oder Briefwechsel auf Grundlage der Heiligen Schrift auszuräumen oder auf einer allgemeinen Konferenz die Streitfragen zu schlichten. ${ }^{8}$ Nach der Konferenz von Karthago 411 sind nur noch zwei Briefe Augustins an Donatisten bekannt. In ihnen steht die Einladung zur Rückkehr in die Kircheneinheit im Vordergrund. ${ }^{9}$

In einigen Briefen an katholische Bischöfe und Laien findet das donatistische Schisma ebenfalls Erwähnung. ${ }^{10}$ Es ist auffällig, dass mit zwei Ausnahmen (epp. 53, 144) die Geschichte der Kirchenspaltung in diesen Schreiben kein Thema ist. Sowohl gegenüber Laien als auch Bischöfen und anderen Klerikern werden entweder theologische oder aktuelle kirchenpolitische Fragen abgehandelt. Oftmals ist der Donatismus nicht das Hauptthema, sondern die Bezüge sind eher beiläufig, wie etwa die Erwähnung von Gewalttaten der Circumcellionen (epp. 29, 35, 111). Häufig werden Fragen der Konversion angesprochen, seien es Probleme beim Übertritt von Klerikern oder aber positive Reaktionen

$5 \mathrm{Zu}$ Augustins Kontakten und Korrespondenzen mit donatistischen Bischöfen vgl. Poss. vita 9; ep. 43.1; dazu Crespin, Ministère, 144-155. - Die donatistischen Briefpartner reagierten häufig nicht auf Augustins Briefe (epp. 35.1; 87.6). In einigen Fällen bat Augustinus um Vermittlung durch Laien, so einen gewissen Naucellio (ep. 70.1), Eusebius (ep. 34, 35) oder Herotes (ep. 49.1); vgl. Crespin, aaO, 151. Bekannt ist indessen ein Brief des Bischofs Macrobius als Antwort auf Augustins ep. 106 (vgl. ep. 107).

6 Die umfangreiche ep. 108 an Macrobius enthält eine ausführliche theologische Erörterung des Schismas mit zahlreichen Verweisen auf das Maximianistische Schisma.

7 Vgl. die Ausführungen o. Kap. 2.2.

8 Epp. $23.6-7 ; 33.1-6 ; 34.5-6 ; 35.1 ; 44.6,14 ; 49.1,3 ; 51.1 ; 87.1,6,10 ; 88.10$.

9 Epp. 141, 173. Vgl. dazu u. Kap. 5.4.

10 Insgesamt 19 überlieferte epistulae: Epp. 29, 83 an Alypius; ep. 41 an Aurelius; ep. 53 an Generosus von Cirta; ep. 56, 57 an Celer; ep. 58 an den Senator Pammachius; ep. 61 an den Laien Theodorus; ep. 69 an Castorius; ep.78 an die Gemeinde von Hippo; ep. 85 an Bischof Paulus; ep. 111 an Victorianus; ep. 142 an zwei konvertierte Priester; ep. 144 an die konvertierten Donatisten von Cirta; ep. 208 an Felicia; ep. 209 an Papst Caelestius; ep. 245 an Possidius; ep. 28* an Bischof Novatus. Vgl. auch ep. 11* von Consentius an Augustinus über eine Anfrage hinsichtlich des Umgangs mit den Priscillianisten in Spanien. 
auf vollzogene Übertritte (epp. 58, 61, 69, 78, 245). Dagegen stehen politische Fragen, insbesondere die Umsetzung der antidonatistischen Gesetze nach 405 und 411 im Zentrum der Briefe zum Donatismus, die Augustinus an römische Beamte und Würdenträger schrieb. ${ }^{11}$ Meistens handelt es sich um eine Bestandsaufnahme der gegenwärtigen Situation, verbunden mit einer konkreten Bitte an die Adressaten. Nur in wenigen Schreiben weist Augustinus auch auf historische oder theologische Zusammenhänge hin, wie in ep. 89 an Festus oder in der Abhandlung über die correctio der Donatisten (ep. 185) an Bonifatius.

Im Folgenden werden jene Briefe betrachtet, die für die Darstellung der Geschichte des Schismas und die historische Argumentation Augustins von Bedeutung sind. ${ }^{12}$

\subsection{Im Gespräch mit Donatisten: Die Briefe 43 und 44}

Anfang des Jahres 397 schrieb Augustinus zwei Briefe ${ }^{13}$ an eine Gruppe von Donatisten aus der Umgebung der Stadt Thubursicum in Numidien. ${ }^{14}$ Augustinus befand sich auf einer Besuchsreise durch mehrere Städte, ${ }^{15}$ als er unter

11 Insgesamt 17 überlieferte Epistulae: Epp. 34, 35 an Eusebius, Beamter in Hippo; epp. 86, 151 an Caecilianus; ep. 89 an Festus; epp. 96, 97 an den MO Olympius; epp. 100, 112 an Donatus (Prokonsul 408/9); epp. 128, 129, 133, 139 an den Tribun Marcellinus; ep. 134 an Apringius (Prokonsul 411); ep. 155 an den vicarius Africae Macedonius; ep. 185 (= correct.) an den Tribun Bonifatius; ep. 204 an den Tribun Dulcitius; vgl. dazu Morgenstern, Briefpartner, 106-126.

12 Briefe, die für das Verhältnis Augustins zu den Donatisten und seinen Kampf gegen das Schisma relevant sind, wurden für die Entwicklung des Donatismus zur Zeit Augustins bereits ausgewertet. Vgl. o. Kap. 2.2. Diejenigen Briefe, die infolge der Konferenz von Karthago verfasst worden sind, werden ebenfalls an anderer Stelle betrachtet; s. u. Kap. 5.4.2.

13 Epp. 43, 44. Edition: Goldbacher, CSEL 34.2, 85-121. Zur Datierung vgl. Perler/Maier, $208 \mathrm{f}$.

14 Die colonia Thubursicum Numidarum lag etwa $87 \mathrm{~km}$ südlich von Hippo Regius und $40 \mathrm{~km}$ südöstlich von Thagaste auf einem Hochplateau; vgl. Perler/Maier, 210; Lepelley, Cités II, 210. - In ep. 43 wird kein Ortsname genannt, aber laut ep. 44.1 gehörten die Donatisten zur Diözese des Bischofs Fortunius von Thubursicum. - Die epp. 43 und 44 werden oftmals mit den Thiavensibus duas in Poss. Ind. VI 29 identifiziert. Demzufolge wären die Adressaten Bewohner der kleinen Ortsgemeinde Thiava. Für diese These spricht der inhaltliche Zusammenhang: Im Indiculus werden die Briefe unter der Überschrift Adversus Donatistas aufgeführt. Die geographische Nähe von Thubursicum und Thiava lässt ebenfalls auf eine Übereinstimmung schließen (vgl. Lepelley, Cités II, 210). Die Thiavensibus duas könnten auch verlorene Briefe aus einem anderen $\mathrm{Zu}-$ sammenhang sein (so Monceaux VII, 131), doch ist dies weniger wahrscheinlich. D. de Bruyne (Les anciennes collections et la chronologie des lettres de saint Augustin, RevBen 43, 1931, 284-295, hier: 295) hält die Identifizierung für sicher. Ihm folgen u.a. 
anderem auf einige donatistische Laien traf, die eine große Bereitschaft zur Diskussion zeigten (ep. 43.3). In ep. 43 berichtet Augustinus von zwei Gesprächen, in denen er mit diesen Donatisten Fragen zum Schisma erörterte und versuchte, sie zu einer Hinwendung zur katholischen Kirche zu bewegen. Einige Zeit später, während eines kurzen Aufenthalts in Thubursicum, kam es auf Wunsch Augustins zu einem Treffen mit dem dortigen donatistischen Bischof Fortunius, an dem von katholischer Seite unter anderem auch Alypius teilnahm, der sich unter Augustins Begleitern befand. ${ }^{16}$ Über den Verlauf dieses Gesprächs berichtet Augustinus in ep. 44. Beide Briefe geben somit ein eindrucksvolles Zeugnis über die Bemühungen Augustins zu Beginn seines Episkopats, mit Donatisten ins Gespräch zu kommen und die Gründe der Spaltung zu diskutieren. ${ }^{17}$ Zudem stellen die Briefe wertvolle Quellen sowohl für historische Einzelheiten als auch für Art und Weise der historischen Argumentation bei Augustinus dar.

Ep. 43 richtet Augustinus an die Donatisten Glorius, Eleusius, zwei mit Namen Felix und an Grammaticus, ${ }^{18}$ die sich an der Diskussion beteiligt hatten, darüber hinaus aber auch an alle anderen interessierten Leser. Seine Absicht ist es, die in der Diskussion vorgebrachten Argumente zusammenzufassen und den Gesprächspartnern schriftlich mitzuteilen, in der Hoffnung, diese würden sich endlich vom donatistischen Irrtum abwenden und zur katholischen Kirche zurückkehren. (43.1-3). Die allgemein gehaltene Adresse, die einleitenden Worte und die häufigen Appelle zur Umkehr zeigen den Pastoralcharakter des Briefes. Augustinus erwähnt, dass er früher bereits an führende Donatisten Briefe geschrieben habe, die allerdings nicht beantwortet worden seien. Er macht deut-

Mandouze, PAC, 336 f., s. v. Eleusis; Perler/Maier, 210 f. und Morgenstern, Briefpartner, 99, 244 Anm. 1394; vgl. Wilmart, Elenchus, $211 \mathrm{f}$.

15 Vgl. ep. 43.5 (Besuch der Kirche von Gelizitana). Die Reise fand wahrscheinlich im Jahr 396 statt.

16 Beide waren auf dem Weg nach Cirta (44.1), um dort einen neuen Bischof zu weihen (44.13). Perler/Maier (208 f.) setzen diese Reise vor die in ep. 43 beschriebene Fahrt. Monceaux (IV 276, 496; VII, 279) konstruiert aus der Aussage cum ei [Fortunius] renuntiaremus [Augustinus] uolentes eum uidere, non abnuit einen Brief Augustins an Fortunius mit der Bitte um eine Begegnung. Im Zusammenhang wird man jedoch eher an eine mündliche Übermittlung zur Vereinbarung eines Treffens denken.

17 Aufgrund dieser Beispielfunktion werden die Gespräche in der Literatur oft als positives Beispiel einer Annäherung beider Kirchen herangezogen. Vgl. Crespin, Ministère, 148-152; Lamirande, Studia canonica 32, 1998, 214-218; Lancel, Augustin, 267; van der Meer, Augustinus, 143 f. [mit stark antidonatistischer Färbung!]; Monceaux IV, 69, 275 279, VI; 297-303 [mit sehr großzügigen Interpretationen]; Grasmück, Coercitio, 180 183.

18 Keiner dieser Adressaten ist (abgesehen von ep. 44) anderweitig bekannt. Mandouze verzeichnet zwei der Adressaten namentlich: PAC, $336 \mathrm{f}$, s. v. Eleusis; $542 \mathrm{f}$., s. v. Grammaticus. 
lich, dass er die Sorge um die einzelnen Menschen als Ausgangspunkt seiner Tätigkeit ansieht (43.1).

Augustins Brief stellt zwar kein Protokoll der Diskussionen mit den Donatisten dar, aber sein Argumentationsaufbau und die Entgegnung auf einige Zwischenbemerkungen, die während des Gesprächs gefallen waren, geben den Inhalt des Treffens im Großen und Ganzen wieder. Durch die Sichtweise Augustins erfahren wir nur wenig über die Motivation der Donatisten und über ihre Urteile und Bemerkungen während des Gesprächs. Augustins Gesprächspartner waren aber offensichtlich dazu bereit, ohne dogmatische Vorbehalte die Gründe der Kirchenspaltung zu erörtern und eigene Positionen kritisieren zu lassen. Sie erwarteten vom Katholiken eine überzeugende Darstellung seiner Position, ${ }^{19}$ vielleicht teilten sie sogar sein Ansinnen, gemeinsame Lösungen für die Überwindung des Schismas zu finden.

Im Zentrum der Diskussion standen nicht die theologischen Fragen, sondern die Geschichte des Schismas. Nachdem die Donatisten auf die Absetzung Caecilians durch das karthagische Konzil hingewiesen hatten (43.3), referierte Augustinus seine Sicht der causa Caeciliani mit den bischöflichen und kaiserlichen Urteilen zu Gunsten der Katholiken. Da er jedoch keine schriftlichen Dokumente zum Beweis seiner Aussagen dabei hatte, ließ er sie beschaffen und in einem zweiten Treffen, zwei oder drei Tage später, den Donatisten vorlesen. Ausführlich wurden die Rolle des Secundus von Tigisi, das Konzil von Cirta, der Fall des Felix von Abthugni und die Urteile der Bischöfe in Übersee und des Kaisers abgehandelt (43.5). Inwieweit über die Dokumente kontrovers diskutiert wurde, lässt sich Augustins Darlegung nicht entnehmen. Wahrscheinlicher als eine lebhafte Auseinandersetzung scheint aber ein predigtähnlicher Vortrag Augustins zu sein, in dem er von einigen Nachfragen unterbrochen die Dokumente interpretierte. ${ }^{20}$

In jedem Fall hatte Augustinus den Eindruck gewonnen, dass seine Anstrengungen auf fruchtbaren Boden gefallen seien und sich eine Fortsetzung der Bemühungen lohnte. In Anknüpfung an die stattgefundenen Unterredungen räumt er der historischen Argumentation in ep. 43 den größten Platz ein. Er interpretiert ausführlich die seinen Adressaten nunmehr bekannten Dokumente, um ihr Verständnis von den Anfängen des Schismas zu widerlegen. ${ }^{21}$ Die Aussagen zur Geschichte münden schließlich in eine theologische Reflexion über das Unheil von Wiedertaufe und Schisma im Gegensatz zur christlichen

19 Vgl. ep. 43.5: Sed quia haec omnia dicebamus tantum, non etiam legebamus, minus profecto uobis agere uidebamur, quam de nostra expectabatis instantia.

20 Monceaux (VI, 299) übersieht den mit Sicherheit bestehenden Unterschied zwischen dem Gesprächsablauf und dem Predigtstil der ep. 43 (insbesondere am Schluss), wenn er folgert: „Le procès-verbal de la controverse se terminait par un sermon; et le sermon, par une mise en demeure de se convertir.“

21 Ep. 43.6-20. Vgl. u. Kap. 4.2.1. 
Einheit, in der gute und schlechte Menschen geduldet werden sollten (43.2124). Diese bekannten Formeln ergänzt Augustinus um Hinweise auf die Circumcellionen, Optatus von Thamugadi und andere Gewalttäter. Obwohl die Donatisten solche Menschen tolerierten, verharrten sie dennoch im Schisma (43.24). Nach einer Zusammenfassung (43.25), verweist Augustinus auf die Parallele des Maximianistischen Schismas (43.26) und ruft zur Einheit auf, in der Hoffnung auf Umkehr seiner Leser (43.27).

Im Gegensatz zu ep. 43 konzipierte Augustinus ep. 44 nicht als Hirtenbrief an Donatisten, sondern richtete ihn aus zwei Gründen direkt an vier seiner Gesprächspartner aus der Diözese Thubursicum. ${ }^{22}$ Zum einen wollte er seine ehemaligen Gesprächspartner über das abgehaltene Streitgespräch mit ihrem Bischof Fortunius ${ }^{23}$ informieren, an dessen Zustandekommen sie nicht unbeteiligt waren $(44.1,3)$. Zum anderen wollte Augustinus die begonnene Diskussion weiterführen, wie er es mit Fortunius vereinbart hatte, und wendet sich nun an die Adressaten mit der Bitte, Fortunius an sein Versprechen zu erinnern, den angefangenen Austausch zum Abschluss zu bringen (44. 2, 13). Offensichtlich hatte Augustinus seit seinem Besuch nichts mehr von dem Donatisten gehört, wünschte aber nach wie vor eine Fortsetzung des Disputs. ${ }^{24}$

Da während der Unterredungen nicht wie gewünscht ein vollständiges Protokoll angefertigt werden konnte, hatte Augustinus die entscheidenden Passagen im Nachhinein aufgezeichnet; und dieses Gedächtnisprotokoll übersandte er nun seinen Adressaten. Durch diesen Protokollcharakter der ep. 44 erhalten wir einen fast vollständigen Überblick über die einzelnen Diskussionspunkte und damit auch Einblick in einige Positionen der Donatisten.

Das Treffen zwischen Fortunius und Augustinus und seinen Begleitern fand im Haus des Donatisten statt. Offensichtlich sprach sich dieses Ereignis schnell herum, denn Augustinus berichtet von einer großen Menge Zuhörer, die herbeiströmten, um dem Disput beizuwohnen. Dabei ärgerte er sich über diejenigen, die nicht aus aufrichtigem Interesse, sondern aus Schaulust gekommen waren und durch Zwischenrufe und Lärmen die Unterredung störten. Nachdem die Katholiken die Anfertigung eines Protokolls verlangt hatten, wehrte sich Fortunius zunächst dagegen, stimmte dann aber doch zu. Die Schreiber gaben

22 Die Adresse von ep. 44 nennt Glorius, Eleusis und die beiden Felix, die aus ep. 43 bekannt sind. Es fehlt hier jedoch ein Zusatz für einen größeren Leserkreis.

23 Mandouze, PAC, 500-502, s. v. Fortunius 2.

24 Ep. 44.13: unde uos hortor et obtestor per domini sanguinem, ut eum [Fortunium] promissi sui commoneatis et gnauiter instetis, ut res coepta peragatur, quam prope ad finem peruenisse iam cernitis. - In ähnlicher Weise bat Augustinus den Laien Eusebius um Vermittlung eines Gespräches mit Proculeianus, dem donatistischen Bischof von Hippo (epp. 34, 35). - Lamirande (Studia canonica 32, 1998, 216) meint, Augustinus habe Fortunius selbst eine Kopie des Protokolls zukommen lassen. Es heißt aber eindeutig in ep. 44.2: potestis [die Adressaten] enim ei [Fortunius] litteras meas legere. 
jedoch aufgrund der immer größeren Unruhe und heftigeren Auseinandersetzung nach einiger Zeit auf (44.1-2). ${ }^{25}$ Diesen Mangel gedachte Augustinus mit der späteren Abfassung von ep. 44 auszugleichen.

Während in der Diskussion mit den Laien von Thubursicum die Geschichte des Schismas im Vordergrund stand, wurde dies im Gespräch mit Fortunius nur am Rande angeschnitten (vgl. 44.8). Im Zentrum standen Fragen zum Kirchenverständnis, zur Verfolgung und zum Taufsakrament. Fortunius, der bereits ein alter Mann war, hatte von Augustins Gesprächspartnern aus seiner Diözese lobende Worte über den Bischof von Hippo gehört und drückte zu Beginn des Gesprächs seinen Respekt vor Augustinus aus. Er akzeptierte ihn als Gesprächspartner (44.3), im Gegensatz zu den häufigen Verweigerungen oder polemischen Angriffen gegen Augustinus durch andere Donatisten.

Als erstes erörterten die beiden Bischöfe die Frage nach der wahren Kirche. Augustinus stellte die weltweite Verbundenheit der katholischen Kirche heraus, die auf der anderen Seite auch Fortunius für die Donatisten behauptete. Fortunius begründete die Rechtmäßigkeit der Donatisten durch ihre Rolle als verfolgte Kirche unter Heranziehung der biblischen Verheißung für diejenigen, die um der Gerechtigkeit willen verfolgt werden. ${ }^{26}$ Augustinus hielt dagegen, dass die Donatisten nur eine gerechte Verfolgung hätten erleiden können, wenn sie sich nicht zuvor von der Kirche des Erdkreises getrennt hätten, und forderte nunmehr, Fortunius solle klären, ob die Donatisten noch in der Kircheneinheit gelebt hätten, als die Verfolgung durch Macarius stattfand. Fortunius aber lenkte das Gespräch auf die Traditorenfrage und die Schuld der Katholiken durch die traditio (44.4). Augustinus lehnte diese Vorwürfe mit Hinweis auf die Gegensätzlichkeit der katholischen und donatistischen Dokumente ab und fragte, wie die Donatisten ihre Trennung von den schuldlosen Kirchen in anderen Provinzen rechtfertigten.

„[Fortunius antwortete], dass die Kirchen in den überseeischen Provinzen so lange unschuldig geblieben seien, bis sie zu jenen Bluttaten ihre Zustimmung gegeben hätten, die, wie er sagte, sich während der macarianischen Verfolgung zugetragen hätten. ${ }^{\text {‘27 }}$

Aus Augustins Sicht war diese Antwort eine Bestätigung für die Trennung der Donatisten von den Kirchen in Übersee. Interessant ist allerdings das Argument

25 Grasmück (Coercitio, 183) verallgemeinert in unzulässiger Weise, wenn er behauptet, aufgrund von „lärmenden Volksscharen“ hätten Gespräche „nie“ zu Ende geführt werden können, es sei denn, man habe sich „in aller Stille“ treffen können. - Zu den notarii vgl. Teitler, Notarii et exceptores, $191 \mathrm{f}$.

26 Ep. 44.3. Vgl. die Argumentation bei Cresconius (Kap. 3.3.4).

27 Ep.44.5: [Fortunius] respondit tam diu transmarinarum partium ecclesias mansisse innocentes, donec consensissent in eorum sanguinem, quos Macarianam persecutionem pertulisse dicebat. 
des Fortunius: Nicht die Schuldfrage der traditio sei für den Bruch mit den anderen Kirchenprovinzen entscheidend gewesen, sondern die offenkundige Parteinahme der dortigen Christen für die Verfolgung der Donatisten in Afrika. Damit argumentierte Fortunius nicht wie Cresconius mit einem Hinweis auf eine falsche, nichtcyprianische Taufpraxis der überseeischen Kirchen, durch die eine communio ausgeschlossen sei ${ }^{28}$ sondern mit einem anderen donatistischen Grundsatz: die alleinige Rechtmäßigkeit der verfolgten Kirche. Eine Kirche, die sich auf die Seite der Verfolger stellt, konnte für Fortunius nicht mehr die wahre Kirche sein. ${ }^{29}$

Als Augustinus einen weiteren Nachweis über die Verbindung der Donatisten mit anderen Kirchen vor der Verfolgung des Macarius forderte (44.5), ließ Fortunius eine Schrift heranbringen und daraus das Synodalschreiben der Bischöfe von Serdica verlesen, in dessen Adresse auch der Name Donatus als Bischof Karthagos auftauchte. Augustinus kannte diesen Brief noch nicht, äuBerte sich kritisch über die fehlende Datierung und zweifelte an der Identifizierung des Donatus mit dem gleichnamigen Begründer der Donatisten. Dann stellte er aber mit Hilfe des Alypius fest, dass es sich wohl um einen Brief des arianischen Teils der Synode von Serdica handelte. Zu Prüfungszwecken wollte Augustinus das Buch ausleihen, was ihm jedoch nicht gestattet wurde (44.6). ${ }^{30}$

Im weiteren Gesprächsverlauf wurde über gerechte und ungerechte Verfolgung diskutiert. Fortunius hielt dem donatistischen Verständnis gemäß jede Art von Verfolgung für ungerecht, während Augustinus anhand einiger Beispiele das Vorkommen gerechter Verfolgung nachweisen wollte. Er verwies auf biblische Exempel und auf das Vorgehen der Donatisten gegen die Maximianisten sowie auf die Gewalttaten, die von Donatisten an Katholiken wie auch an eigenen Leuten verübt worden seien. Fortunius leugnete derartige Gewalttaten und konfrontierte Augustinus umgekehrt mit einem Beispiel aus der Anfangszeit des Schismas, als Anhänger Caecilians angeblich einen Interimsbischof (interventor) der Donatisten ermordet hätten (44.7-9). ${ }^{31}$ Schließlich wurden noch einige Fragen gegenwärtiger Auseinandersetzungen besprochen. Augustinus betonte seinen Willen zum Dialog und lud auch Fortunius zu einer Fort-

28 Vgl. o. Kap. 3.3.3.

29 Crespin, Ministère, 162: „Pour certains, comme Fortunius de Thubursicu, ce grief est le plus grave: ce qui condamne l'Église catholique tout entière, ce n'est pas la communion avec Caecilianus, mais le consentement aux lois et aux poursuites du temps de Macarius.“ Für Fortunius jedoch scheint der Vorwurf der Verfolgung nicht per se der „schwerste“ gewesen zu sein. Der Diskussionszusammenhang (in ep. 44.4-5) zeigt, dass Fortunius, von Augustinus herausgefordert, eine weitere Begründung für die donatistische Abspaltung suchte, nachdem er mit der traditio-Beschuldigung nicht weitergekommen war.

30 Zum Synodalbrief aus Serdica vgl. o. Kap. 3.3.3.

31 Dazu ausführlich u. Kap. 7.1.2. 
setzung des fruchtbaren Gesprächs ein (44.11-14). Er zerstreute die Befürchtungen weiterer Verfolgungen der Donatisten ohne Einschränkung und betonte die Notwendigkeit von Liebe und Geduld zum Erlangen der Kircheneinheit.

Augustinus scheint einen positiven Eindruck von seinem Gesprächspartner mitgenommen zu haben, wohl auch, weil Fortunius am Ende des Gesprächs andeutete, dass er mit der inzwischen stets vollzogenen Wiedertaufe an Katholiken nicht einverstanden sei und letztlich doch zugab, dass von einzelnen Donatisten Gewalt verübt werde, der er ablehnend gegenüberstehe. Augustinus freute sich auch über das gemeinsame Ergebnis, sich die Gewalt anderer nicht gegenseitig zum Vorwurf zu machen (44.12). Am Ende seines Briefes stellt Augustinus nochmals deutlich den Wunsch heraus, durch eine Konferenz von Vertretern beider Parteien ungestört alle Fragen des Schismas zu erörtern (44.14). Der begonnene Dialog solle weitergeführt werden, denn er sei fast schon zum Abschluss gelangt (44.13).

Das Gespräch zwischen Fortunius und Augustinus scheint offenbar in einer guten Atmosphäre verlaufen zu sein, nicht zuletzt aufgrund Augustins moderaten Tonfalls. Dennoch entsprach der von Augustinus verbreitete Optimismus nicht den realen Voraussetzungen für zukünftige Gespräche. Auch wenn es am Ende zu Annäherungen gekommen war, wie zum Beispiel in der gemeinsamen Ablehnung von Gewalt, so wurden die grundsätzlichen Differenzen in keiner Weise überbrückt. Die unterschiedliche Beurteilung von Katholizität oder gerechter Verfolgung treten in dem Protokoll deutlich hervor und stehen genauso unversöhnlich gegenüber wie Augustins Positionen gegenüber denen eines Petilianus oder Cresconius. Nicht zu vergessen bleibt, dass die Fragen der traditio und der Entstehung des Schismas ausgeklammert wurden. ${ }^{32}$

\subsection{Auseinandersetzung mit donatistischen Bischöfen: Die Briefe 87 und 88}

Um das Jahr 403 versuchte Augustinus, einen Kontakt zu Emeritus, dem Bischof von Caesarea in Mauretanien und einem der führenden Donatisten, herzustellen. ${ }^{33}$ Auf einen ersten Brief, der nicht erhalten ist, hatte Augustinus keine

32 Monceaux (VI, 299f.) und ihm folgend van der Meer (Augustinus, $143 \mathrm{ff}$.) beurteilen Fortunius als naiven, ungelehrten, alten Mann, der gar nicht begriffen habe, worum es ging, und Augustinus nichts entgegenzusetzen hatte. Mag Fortunius auch nicht die Eloquenz eines Petilianus besessen haben, diese Deutung ist dennoch überzogen. Monceaux und van der Meer übersehen die einseitige Herausstellung der eigenen Positionen durch Augustinus und missverstehen die ekklesiologischen Grundlagen der donatistischen Argumente.

33 Emeritus war ein Wortführer des Konzils von Bagaï und 411 einer der offiziellen Vertreter der Donatisten in Karthago. Nach der Konferenz verfasste Augustinus eine Schrift gegen Emeritus, die nicht erhalten ist (retr. II 46; Poss. indic. VI 18). Am 20.09. 
Antwort erhalten (87.6). Nun unternahm er mit ep. 87 an den „geehrten und geliebten Bruder" einen weiteren Versuch, mit dem Donatisten ins Gespräch zu kommen. ${ }^{34}$ Augustinus schätzt Emeritus als einen sehr gebildeten Mann und macht aus seiner Hochachtung keinen Hehl. Geradezu begierig hofft er darauf, ihn kennenzulernen und mit ihm einen sachlichen Dialog führen zu können. ${ }^{35}$

Das Thema des Briefes ist die Frage, wie mit Sündern in der christlichen Kirche umgegangen werden soll. Augustinus setzt zwei bekannte Streitfragen in den Mittelpunkt seiner Ausführungen: zum einen das Verhältnis der donatistischen Partei zur weltweiten Kirche, zum anderen das Verständnis von Verfolgung. Bezüglich der ersten Frage erörtert Augustinus das Paradox, dass die Donatisten die gesamte Christenheit verurteilten, ohne ihre Anklagen zu beweisen, und umgekehrt nachweisliche Sünder in ihren eigenen Reihen duldeten. Er unterstreicht seine Position, dass kein Sünder die ganze Gemeinschaft der Christen verunreinigen könne und appelliert an Emeritus' Gelehrsamkeit, die Aussagen der Heiligen Schrift dahingehend zu überprüfen. Emeritus werde dadurch die Grundlosigkeit des Schismas erkennen (87.1-3). Im Anschluss

418 traf Augustinus mit Emeritus in Caesarea für einen Disput zusammen (vgl. Emer.; s. Caes. eccl. und retr. II 51; s. u. Kap. 5.4.4). Zur Person: Mandouze, PAC, 340-349, s. v. Emeritus 2; Monceaux VI, 145-189; Lancel, AL 2, 802-804, s. v. Emeritus.

34 Edition: Goldbacher, CSEL 34.2, 397-406. Beide Briefe verzeichnet Possidius (indic. VI 26). Zu ep. 87 vgl. Monceaux VI, 148-152; Mandouze, PAC, 340 f.; Grasmück, Coercitio, $205 \mathrm{f}$; Willis, Augustine, $64 \mathrm{f}$.

Die Datierung des Briefes ist schwierig. Goldbacher (CSEL 58, 26) und Monceaux (VII, 282) geben zu Recht das Jahr 411 als terminus ante quem an, da Augustinus Emeritus noch nicht persönlich kannte, als er den Brief schrieb (vgl. 87.10), ihm aber 411 in Karthago begegnete. Nicht stichhaltig sind Goldbachers und Monceaux' Datierungen nach 405 aufgrund der Anspielung auf kaiserliche Maßnahmen gegen Donatisten in ep. 87.8 (vgl. Monceaux VI, 148: „,vers 405“, dagegen VII, 282: „entre 405 et 411“!). Augustinus spricht an dieser Stelle nicht von dem Unionsgesetz, sondern sehr allgemein von den Maßnahmen der christlichen Kaiser. Außerdem verweist er auf den vicarius des Jahres 377 Flavianus und spricht von der Ablehnung unangemessener Gewalt. Diese Zusammenhänge entsprechen sehr stark der Argumentation zur Verfolgung in c. litt. Pet. Die Formulierung von 87.8 weist keinesfalls auf die Zeit der epp. 88, 93 oder 105, da ansonsten der Hinweis auf kaiserliche Legitimation deutlicher ausgefallen wäre. Allerdings wird dadurch eine Zeit bis etwa 406/7 nicht ausgeschlossen. Zudem deuten der sehr moderate Tonfall und Augustins Dialogwunsch auf eine frühere Abfassung, ebenso die Verwendung des Beispiels Optatus und die Argumentation zu den Maximianisten, da die Zuspitzungen der späteren Schriften (nach Cresc.) fehlen, in der vorliegenden Weise aber in ep. 51 an Crispinus (datiert zwischen 400 und 404) oder ep. 53 (datiert um 400, vgl. u. Kap. 4.1.5) vorkommen. Schließlich stellt Augustinus die Frage nach der Apostolizität der Kirche in den Mittelpunkt seiner Anfragen an Emeritus. Dies findet sich in dieser Form in ep. 49 an den Bischof Honoratus und in ep. 52 an Severinus, die beide sicherlich vor 405 datiert werden müssen. M. E. ist daher für ep. 87 eine Datierung um 403/4 am wahrscheinlichsten. 
verdeutlicht Augustinus seine Haltung anhand der Beispiele Optatus' von Thamugadi (87.4-5) und der Maximianisten (87.6).

Bezüglich der persecutio weist Augustinus auf die Unterscheidung von gerechter und ungerechter Verfolgung hin. Die entscheidende Frage sei, ob die Donatisten Schuld am Schisma trügen oder nicht, und ob sie um der Gerechtigkeit willen verfolgt würden oder nicht (87.7). Die Maßnahmen gegen die Donatisten seien demnach keine Verfolgung, sondern ein Schutz vor den Gewalttaten seitens der Donatisten. ${ }^{36}$ Unangemessene Härte und fehlende christliche Mäßigung, so Augustinus, missfielen ihm auch, seien aber kein Grund für eine Trennung von der katholischen Kirche (87.8). Die Katholiken akzeptierten trotz der Verurteilung des donatistischen Schismas deren Sakramente, weil diese von Gott gegeben und daher unveränderlich gültig seien (87.9). Schließlich äußert er seine Hoffnung auf eine Antwort und damit auf das Zustandekommen eines Dialogs (87.10).

Die Argumentation im Brief an Emeritus schließt inhaltlich an die Schriften gegen Petilianus an. Die donatistische These der Reinheit der Kirche nimmt Augustinus zum Ausgangspunkt und versucht ihr zunächst mit theologischen Argumenten entgegenzutreten. In einem verhältnismäßig nüchternen, teilweise sogar freundlichen Tonfall erläutert er das katholische Verständnis von Kirche, Taufe und Verfolgung und setzt die donatistischen Aussagen in Gegensatz zu Beispielen aus Bibel und Gegenwart. Man erkennt Augustins Taktik in Bezug auf den direkten Dialog mit Emeritus: Er beginnt mit einer Aufarbeitung der donatistischen Einwände und Vorbehalte gegen die Katholiken. Sein erstes Ziel ist es also, eine gemeinsame Grundlage zu schaffen, anhand derer dann - in einem zweiten Schritt - Ursprung und Anlass des Schismas überprüft werden können, um schließlich in Erkenntnis der wahren Begebenheiten zur Einheit zurückzufinden. Aus diesem Grund übergeht Augustinus in dieser ersten Kontaktaufnahme mit Emeritus die historischen Fragen und sucht Ansätze für eine gemeinsame Basis. Er hofft auf die gemeinsamen Feststellungen: Es gibt in beiden Kirchen Sündlose und Sünder, Verfolger und Verfolgte und die gleichen Sakramente Christi.

36 Ep. 87.8: „Da aber jene Kaiser bei jeder Gelegenheit die Ruchlosigkeit eures Schismas kennen lernen, so verfügen sie gegen euch gemäß ihrer Sorgfalt und Macht, was sie wollen. Denn sie tragen das Schwert nicht umsonst; sie sind Gottes Diener, Beschützer im Zorn gegen jene, die Böses tun." (sed illi principes qualibet occasione cognoscentes uestri schismatis nefas constituunt aduersus uos pro sua sollicitudine ac potestate, quod uolunt. non enim frustra gladium portant; dei enim ministri sunt. uindices in iram in eos, qui male agunt). 
Einen ganz anderen Charakter als der Brief an Emeritus trägt ep. 88 an den donatistischen Primas Numidiens, Ianuarianus von Casae Nigrae, ${ }^{37}$ der offenbar aufgrund der anhaltenden donatistischen Gewalttaten einige Zeit nach dem Unionsgesetz von 405 verfasst wurde. ${ }^{38}$ Absender des Briefes ist der Klerus von Hippo Regius, doch entsprechen die Gedanken und Argumente den Vorstellungen Augustins, der mit Sicherheit an der Abfassung maßgeblich beteiligt war. ${ }^{39}$

Die Verfasser des Briefes beklagen durchgängig, dass die Donatisten und Circumcellionen in bisher nicht bekannter Weise und mit unerhörter Grausamkeit gegen die Katholiken agitierten. Die emotionale Sprache lässt auf eine sehr aufgeheizte Atmosphäre zwischen den Donatisten und Katholiken in Hippo zu diesem Zeitpunkt schließen. Die Absender wollen eine Änderung der Situation und fordern Ianuarianus in seiner Funktion als donatistischer Primas auf, der Gewalt in der Diözese Hippo ein Ende zu setzen. Er solle Antwort geben und seine Position erklären, indem er den Boten dieses Briefes ein Rückschreiben mitgebe (88.11). Wenn er aber dies verweigere, solle entweder er selbst oder ein Beauftragter nach Hippo kommen oder sich zumindest schriftlich an die verantwortlichen Donatisten wenden, um ihnen in ihrer Gewalt Einhalt zu gebieten (88.12). ${ }^{40}$

Der Argumentationsaufbau ist dreigeteilt. An erster Stelle steht die historische Argumentation (88.1-5). Dem Adressaten werden Umstände der Entstehung des Schismas geschildert. Dabei wird besonders herausgestellt, dass die gegenwärtige antidonatistische Gesetzgebung lediglich die Konsequenz aus früheren Urteilen gegen die Donatisten sei ${ }^{41}$ Anschließend folgt eine Erläute-

37 Ianuarianus war wie Emeritus Teilnehmer des Konzils von Bagaï und der Konferenz von Karthago 411. Zur Zeit der Abfassung von ep. 88 war er bereits ein älterer Mann (ep. 88. 1). Zur Person: Mandouze, PAC, 579, s. v. Ianuarianus 1.

38 Edition: Goldbacher, CSEL 34.2, 407-419. Die Identifizierung des Briefes mit Poss. indic. VI 21 (Ianuariano primatui partis Donati) ist sehr wahrscheinlich. Ep. 88 gehört aufgrund seiner historischen Aussagen zu den meistbeachteten Briefen Augustins. Zum Inhalt vgl. Monceaux VI, 294-296; Grasmück, Coercitio, 205 f. - Datierung: Goldbacher (CSEL 58, 26 f.) datiert zu Recht zwischen 406-411, da der Brief nach dem Unionsedikt 405 und vor der Konferenz von Karthago 411 geschrieben wurde. Monceaux (VII, 282) datiert auf 406, da die antidonatistischen Gesetze als recens (88.6) bezeichnet und die donatistische Delegation nach Ravenna von Januar 406 erwähnt werden (88.10; vgl. o. Kap. 2.2). Die Formulierungen über die Gesetze und diese Reise deuten in der Tat auf verhältnismäßig junge Ereignisse, so dass ep. 88 wohl 406/07 geschrieben wurde.

39 Die Kleriker sprechen von Augustinus als „unserem Bischof“ in ep. 88.6-7. Ihre Verfasserschaft ist also nicht nur pro forma. Morgenstern (Briefpartner, 96) übergeht diese Frage und nennt Augustinus als Absender.

40 Im Gegensatz zu Monceaux (VI, 296) verstehe ich diese Vorschläge zur Beendigung der Gewalt in Hippo (88.11-12) nicht als Alternative zu dem grundsätzlichen Vorschlag einer allgemeinen Konferenz in 88.10.

41 Dazu ausführlich unten Kap. 4.2.2. 
rung zu der Gesetzgebung des Jahres 405 (88.6-7). Die Absender beschreiben anhand von Beispielen, wie Terror und Gewalt der Donatisten die ,Wiederbelebung" der Gesetze durch den Kaiser erzwungen hätten (in uos recoli et moueri $).{ }^{42}$ Im dritten Teil der Argumentation wird von der gegenwärtigen Gewalt berichtet, der es zu begegnen gelte (88.8-10). Während die Donatisten die Katholiken gewalttätig bekämpften, täten diese alles, um friedlich zur Einheit aufzurufen. Dennoch fühlten sich die Donatisten als Opfer einer Verfolgung, obwohl sie selbst verfolgten. Ein Ausweg aus dem derzeitigen Dilemma sei ein Zusammenkommen beider Seiten zu einer Konferenz. Die Absender appellieren eindringlich an Ianuarianus, einer solchen Konferenz zuzustimmen (88.10).

Wenn man sich die moderaten Töne Augustins im Gespräch mit Fortunius oder im Brief an Emeritus in Erinnerung ruft, wirken die Sätze in diesem Brief umso schärfer. Die Rechtfertigung der Katholiken für die antidonatistischen Gesetze und die Zwangsmaßnahmen sind nichts anderes als eine Schuldzuweisung auf die Donatisten: diese tragen die Schuld am Schisma, an der fortbestehenden Gewalt und an den Gesetzen. Die Gewalt und die neuen Gesetze dies macht das Schreiben deutlich - haben die Akzente der Argumentation maßgeblich verändert: Die historische Rechtfertigung überlagert hier die einzelnen theologischen Differenzen, die Augustinus in seinen Gesprächen und Korrespondenzen ursprünglich zu lösen gedachte. Gleichwohl bleibt ein Angebot zum Dialog bestehen. Die Idee einer allgemeinen Konferenz wird auch Ianuarianus unterbreitet, genauso wie die Möglichkeit einer schriftlichen Kontroverse. Man darf aber daran zweifeln, dass Ianuarianus in irgendeiner Form auf diesen Brief reagierte.

\subsection{Aufruf zur Umkehr: Die Briefe 76 und 105 an die Donatisten}

Die drei überlieferten Briefe, mit denen sich Augustinus an die donatistischen Laien richtete, geben einen sehr guten Einblick in Veränderungen von Augustins Argumentationsansätzen, da sie zu unterschiedlichen Phasen seines antidonatistischen Kampfes verfasst wurden, der erste Brief in der Zeit vor dem Unionsgesetz (ep. 76), der zweite einige Zeit danach (ep. 105) und schließlich der dritte nach der Konferenz von 411 (ep. 141). Formal handelt es sich um Traktate, knapp und übersichtlich, in einfacher Sprache und mit erläuternden Beispielen verfasst, die in möglichst vielen Exemplaren unter das Volk gebracht werden sollten. Es gab keine konkreten Empfänger, aber dort, wo es Augustinus und seinen katholischen Kollegen möglich war, sollten die Traktate abge-

42 Zur historischen Auswertung dieses Teils s. o. Kap. 2.2.1. 
schrieben und in Umlauf gebracht werden, sei es durch öffentliche Anschläge oder durch Weitergabe an lesekundige Laien in der Gemeinde. ${ }^{43}$

Ende des Jahres 403 wandte sich Augustinus mit der kurzen ep. 76 an die donatistischen Gläubigen. ${ }^{44}$ Das Schreiben trägt weder Adressat noch Absender, jedoch werden gleich im ersten Satz die Donatisten angesprochen (76.1), am Schluss konkret die Laien (76.4). Außerdem weisen Stil und Inhalt eindeutig auf ein weniger gebildetes Publikum aus theologischen Laien hin. Augustinus kleidet den gesamten Text in die rhetorische Figur einer Prosopopöie der katholischen Kirche an die Donatisten und trägt in einfachen, bildhaften Worten und fast lakonischer Kürze seine Thesen und Argumente gegen das Schisma vor: Die katholische Kirche sei nicht auf Afrika beschränkt, sondern umfasse den gesamten Erdkreis, und in dieser Kirche lebten „Weizen und Unkraut“ nebeneinander, bis Christus die Trennung vornehme. Die Donatisten aber hätten sich gegen die Einheit der Kirche gewandt und dieser Trennung vorgegriffen; als Unkraut klagten sie nun den Weizen an (76.1-2). Die Schuld zeige sich bei den Vorfahren der Donatisten. Sie hätten, obwohl selbst Traditoren, Caecilianus verurteilt und so Bischof gegen Bischof gestellt und Altar gegen Altar errichtet. Trotz der Urteile europäischer Bischöfe und des Kaisers gegen sie, seien diese Verleumder nicht von ihrem Frevel abgerückt (76.2). Schließlich sei die Furcht vor einer Vermischung von Guten und Bösen unbegründet, denn auch bei den Donatisten seien die Maximianisten nach ihrer Verurteilung wieder aufgenommen und ein Verbrecher wie Optatus von Thamugadi sei toleriert worden. Wie könnten also die Donatisten den Katholiken bis heute die traditio vorwerfen, aber die Maximianisten wieder aufnehmen, die Verfolgung anprangern, aber selber mit Hilfe des Kaisers die Maximianisten verfolgen, die Taufe ablehnen, aber die Taufe verurteilter und zurückgekehrter Maximianisten

43 Damit stehen diese Briefe in einer Reihe mit den verlorenen Traktaten zum Maximianistischen Schisma (retr. II 27-29). Insbesondere ep. 76 mit einem Umfang von nur vier Paragraphen war mit Sicherheit für eine große Vervielfältigung gedacht. - Monceaux (IV, 271; VII, 142, 145) bezeichnet die drei Briefe nicht zu Unrecht als „Manifeste“ und „Proklamationen“, weniger zutreffend dagegen ist m.E. die Bezeichnung „Avertissement“ (IV, 272; VI, 276). - Morgenstern (Briefpartner, 101 f., 246 Anm. 1418) geht mit keinem Wort darauf ein, wie die „Donatistae“ als „Briefpartner“ Augustins zu verstehen sind und in welcher Art die Verbreitung stattfand. - Zu ep. 141 vgl. u. Kap. 5.4.2.

44 Edition: Goldbacher, CSEL 34.2, 324-328; vgl. Monceaux IV, 271.

Datierung: Als terminus ante quem dürfte 405 sicher sein, da Augustinus ansonsten auf die kaiserlichen Maßnahmen nach dieser Zäsur eingegangen wäre und seine Argumente eine andere Zielrichtung eingenommen hätten. In 76.4 erwähnt Augustinus, dass die donatistischen Bischöfe nicht mit den Katholiken sprechen wollten. Monceaux (VII, 281) stellt diese Aussage zu Recht in Zusammenhang mit der Ablehnung des katholischen Gesprächsangebots vom August 403 und datiert ep. 76 auf Ende 403. So auch Goldbacher (CSEL 58, 23); Perler/Maier, 249. 
anerkennen (76.3-4)? Augustinus appelliert eindringlich an die Leser, sich vom gottlosen Schisma ${ }^{45}$ abzuwenden und zur Einheit zurückzukehren. Die Prosopopöie verstärkt den ermahnenden Charakter zusätzlich: Die Kirche selbst klagt über das verdammungswürdige Schisma und lobt im Gegensatz dazu den Frieden der Einheit. Das Schisma gehe auf menschliche Verleumdungen zurück, der Friede auf das Wort Gottes: Die Gläubigen sollen dem sermo dei vertrauen, nicht dem sermo hominum (76.1).

Alle entscheidenden Argumente Augustins gegen die Donatisten finden sich hier auf engem Raum versammelt: Dieser Traktat ist gleichsam eine Kurzlektion antidonatistischer Argumentation für den einfachen Gläubigen. Mit fünf Thesen sollten die donatistischen Laien überzeugt werden: 1. Die Kirche umfasst den gesamten Erdkreis und nicht nur Afrika, 2. Die Kirche umfasst Sünder und Gerechte, 3. Auch bei den Donatisten mischen sich Sünder und Gerechte, 4. Anders lautende Aussagen der Donatisten lassen sich leicht widerlegen, 5. Folglich ist das Schisma grundlos.

In Intention und Argumentation ähnelt ep. 76 stark dem Psalmus contra Partem Donati: Der Ruf zur Einheit und das Leitbild von Spreu und Weizen setzen auch hier den Hauptakzent, und auch im Psalmus spricht die Mutter Kirche den Schlussappell an die verlorenen Kinder. ${ }^{46}$ Der pastorale, ermahnende und ermutigende Charakter des Traktats hebt den versöhnenden Gestus hervor, mit dem Augustinus den Laien gegenübertritt. Die direkte Kritik gilt nicht den Gläubigen, sondern allein dem Zustand der Spaltung und den dafür Verantwortlichen, namentlich den donatistischen Bischöfen, die sich dem Gespräch verweigert hatten. Wenn die donatistischen Wortführer ihren Irrtum nicht einsehen wollten, so könne vielleicht der einfache Gläubige überzeugt werden.

Die Voraussetzungen hatten sich geändert, als Augustinus wohl um das Jahr 408 mit ep. 105 einen weiteren Brief an die donatistischen Laien richtete. ${ }^{47}$ Die

45 Es finden sich hier zahlreiche Wendungen: ep. 76.1: nefarium sacrilegium schismatis; 76.2: praecisio sacrilega; scelus; 76.3: scelus schismatis; nefarius furor; 76.4: sacrilegium schismatis.

46 Vgl. o. Kap. 1.1.

47 Edition: Goldbacher, CSEL 34.2, 595-610. Die Formulierungen presbyteri partis uestrae (105.1) und clerici uestri (105.3) bestätigen die donatistischen Laien als Adressaten. Zudem sprechen wiederum Inhalt und Argumentationsaufbau für diese Zielgruppe. Die Beispiele für donatistische Gewalt in ep. 105 deuten möglicherweise darauf, dass die Laien der Diözese Hippo besonders im Blickfeld Augustins standen. - Zu ep. 105 vgl. Monceaux IV, 272; VI 276; Grasmück, Coercitio, 212-214. - Datierung: Nach ep. 105. 3, 7, 10 dürfte der Brief nach dem Unionsgesetz von 405 (vgl. dazu o. Kap. 2.2.2) geschrieben worden sein. Monceaux (VII, 283) datiert auf Anfang 409 nach den verschärften Gesetzen von 408, Grasmück (Coercitio, 212 Anm. 257) auf Anfang 409. Es gibt allerdings keine sicheren Indizien für diese Spätdatierung. 
angespannte Situation in den donatistischen Gemeinden nach der Verkündigung der antidonatistischen Gesetze von 405 steigerte auch die Konfrontationshaltung gegenüber den Katholiken. Donatistische Priester hatten Augustinus unter Mordandrohung davor gewarnt, weiterhin mit donatistischen Gläubigen in Kontakt zu treten $(105.1-2,17)$. Augustinus antwortete auf diese Warnung mit dem Traktat an die Laien: „Die Liebe Christi erlaubt uns nicht zu schweigen“, beginnt er das Schreiben, auch gegen den Hass müsse der Frieden gepredigt werden. $^{48}$

Augustinus verfolgte nach wie vor das Ziel, Donatisten durch Überzeugungsarbeit zur Rückkehr in die katholische Kirche zu bewegen. Jedoch waren die Hürden für ihn höher geworden. Die Gesetze gegen die Donatisten bestärkten die Donatisten in ihrer Opferrolle und Märtyrermystik, und die Vorbehalte gegen die Katholiken und ihre Friedensappelle wuchsen. Ep. 105 zeigt deutlich das Bemühen Augustins, diese Vorbehalte auszuräumen und sich trotz dieser Situation bei den donatistischen Laien Gehör zu verschaffen.

Augustinus klärt mithilfe eines Bildes zwei Voraussetzungen für die donatistischen Laien: Zum einen beruft er sich auf das gemeinsame Taufsakrament, mit dem die Gläubigen stets mit der (katholischen) Kirche Christi verbunden seien. Zum anderen setzt er, wie bereits in ep. 76, die donatistischen Gläubigen deutlich von ihren Bischöfen und Priestern ab. Die Laien seien nur irregeführte Schafe, die nichts zu befürchten hätten, im Gegensatz zu ihren Verführern, die eine gerechte Strafe erhielten. Die Leser des Traktats, die einfachen Gläubigen, sollten durch die folgenden Ausführungen Augustins die Lügen der Verführer erkennen und sich selbst als Verführte begreifen, die jedoch ohne Furcht vor den antidonatistischen Gesetzen zur katholischen Einheit zurückkehren können. ${ }^{49}$

Entsprechend zieht sich die Gegenüberstellung von Wahrheit und Lüge als roter Faden durch den gesamten Text. Als Autorität für die Wahrheit greift Augustinus auf die Heilige Schrift zurück, da er deren Unantastbarkeit bei allen gleichermaßen anerkannt sah. Auf dieser gemeinsamen Grundlage hofft er, die Donatisten von der Notwendigkeit der Kircheneinheit überzeugen zu können. Seine Schlussfolgerungen demonstriert er im folgenden Syllogismus:

„Durch die Schriften lernen wir Christus kennen, durch die Schriften lernen wir die Kirche kennen. Wir haben die Schriften gemeinsam. Warum behalten wir nicht gemeinsam mit ihnen auch Christus und die Kirche? ‘50

48 Ep. 105.1: Caritas Christi [...] tacere nobis non permittit.

49 Vgl. auch die Exhortatio in 105.13.

50 Ep. 105.14: in scripturis didicimus Christum, in scripturis didicimus ecclesiam. has scripturas communiter habemus; quare non in eis et christum et ecclesiam communiter retinebus? - Sinngemäß wiederholt im Schlussappell (105.17): ecce scripturae communes, ecce ubi nouimus Christum, ecce ubi nouimus ecclesiam. 
Im Gegensatz dazu beruhe die donatistische Lehre von der Spaltung auf weitaus geringeren Autoritäten, nämlich allein auf menschlichen Denken und Handeln. ${ }^{51}$

Augustins Intention ist es nun, mit Hilfe der Heiligen Schrift die Grundpositionen der Donatisten zu erschüttern und als menschliche Lügen und Verleumdungen zu diskreditieren. Unter diesem Aspekt betrachtet er in ep. 105 die bekannten Themen: Er widerlegt die donatistischen Ansichten über die katholischen Traditoren (105.2), die ungültigen Taufen (105.12) und über die Reinheit der donatistischen Kirche in Afrika (105.14-16). Den mit Abstand größten Umfang nimmt allerdings die Frage der Verfolgung ein, die Augustinus zu einer ausgiebigen Apologie der antidonatistischen Gesetze ausweitet (105.311). Zweifellos handelte es sich zur Zeit der Abfassung um das aktuellste und drängendste Problem.

In der Konfrontation von Lüge und Wahrheit verwendet Augustinus Bibelzitate und Beispiele $\mathrm{zu}$ den einzelnen Themen, die auch aus anderen Schriften bekannt sind. ${ }^{52}$ In Bezug auf die Verfolgung treten die historische Argumentation und Beispiele gegenwärtiger Gewalt an die Seite der theologischen Aussagen. Augustinus möchte beweisen, dass die donatistische Selbstdarstellung als unverschuldet verfolgte Kirche der Märtyrer eine Lüge darstellt, dass in Wahrheit die Zwangsmaßnahmen von den Donatisten selbst verschuldet seien $(105.8-10) .^{53}$

Neben der Frage zur Ursache der Verfolgung ist Augustinus auch darum bemüht, die Differenz zwischen der donatistischen Gewalt und der Zwangsgewalt kenntlich zu machen. An erster Stelle steht wiederum die Berufung auf die Heilige Schrift, in der Christus verkündet wird, von dem die Kirche ihre Gewalt erhalte. Der Ursprung und die Legitimation der Gewalt sieht Augustinus also in der Autorität Christi. ${ }^{54}$ Er geht aber noch einen Schritt weiter, um zu beweisen,

51 Ep. 105.2, 6, 14, 17.

52 So stellt Augustinus die traditio-Anklage gegen die Katholiken der Verheißung Christi zur weltweiten Kirche gegenüber (105.2). Zur Verteidigung des katholischen Taufverständnisses beschwört er einmal mehr die Gültigkeit des Sakraments durch Gottes Gnade, unabhängig von der Würde des Priesters. Die biblischen Allegorien vom Spreu und Weizen sowie der Fische im Netz dienen ihm zur Darstellung der Mischung von Sündern und Gerechten in der Kirche (105.16). Mit einer Fülle von über zwanzig Zitaten aus dem Alten und Neuen Testament demonstriert Augustinus die Zusammengehörigkeit von Christus und der Kirche und ihre Verbreitung unter allen Völkern (105.14-15).

53 Zur historischen Argumentation u. Kap. 4.2.2.

54 Ep. 105.6: „Wir hoffen indessen auf keine menschliche Gewalt, auch wenn es wesentlich ehrenwerter ist, seine Hoffnung auf die Kaiser zu setzen als auf die Circumcellionen, seine Hoffnung auf die Gesetze zu setzen als auf Aufruhr, sondern wir erinnern uns, dass geschrieben ist: ,Verflucht ist jeder, der seine Hoffnung auf den Menschen setzt'.[...] Deswegen machen wir Gebrauch von dieser Gewalt der Kirche, die der Herr ihr ver- 
dass selbst die kaiserliche Gewalt keine menschliche Gewalt darstelle, sondern lediglich die potestas Christi in ihrer weltlichen Anwendung. Wenn ein Kaiser sich an die Wahrheit halte, dann seien seine Befehle auch zur Durchsetzung der Wahrheit da. ${ }^{55}$ Auf diese Weise werde es zur Aufgabe des christlichen Kaisers, Religion zu predigen und Gottlosigkeit zu verbieten (105.7). Mehr noch: Der Kaiser werde zum Sprachrohr Gottes und alle Gesetze beruhten auf der göttlichen Autorität (105.11-12).

Ep. 76 und ep. 105 weisen in der Argumentation große Übereinstimmungen auf. Augustinus verfolgte mit beiden Traktaten das gleiche Ziel, donatistische Laien zu überzeugen, in die katholische Kirche überzutreten. Es finden sich Parallelen in der Verwendung der Bibelzitate und Vergleiche sowie in der pastoralen Sprache, den Ermahnungen und Appellen. Auch die grundlegende Argumentationsstrategie ist gleich: Auf der Basis der Heiligen Schrift skizziert Augustinus sein Bild der katholischen Kirche und überprüft anschließend die historischen Taten und die Doktrin der Donatisten an diesem Ideal. Das Ergebnis dieser Überprüfung lautet: Der Exklusivismus der Donatisten steht im Widerspruch zur Heiligen Schrift und zu ihrem eigenen Handeln.

Trotz dieser Gemeinsamkeiten ist eine deutliche Akzentverschiebung sichtbar. Die Tauffrage wird in ep. 105 nur kurz angesprochen, und einige Beispiele über die Duldung von Sündern bei den Donatisten (Optatus, Maximianisten), die andernorts eine wichtige Rolle spielen, fehlen ganz. Stattdessen wird die Verfolgungsthematik in den Vordergrund gestellt und im Hinblick auf die neue Gesetzgebung in veränderter Form interpretiert. Entgegnet Augustinus in den früheren Schriften auf die Verfolgervorwürfe vor allem mit Gegenklagen (Verfolgung der Maximianisten) oder durch Leugnung der Verantwortung (im Falle der macarianischen Verfolgung), so rechtfertigt er in ep. 105 und anderen Schriften nach 405 die Zwangsmaßnahmen als Reaktion auf donatistische Gewalt und als Konsequenz aus dem donatistischen Widerstand gegen das kaiserliche Urteil in der Frage des Schismas.

sprochen und gegeben hat." (de nulla quidem nos hominis potestate praesumimus, quamuis utique multo sit honestius praesumere de imperatoribus quam praesumere de Circumcellionibus, praesumere de legibus quam praesumere de seditionibus; sed meminimus scriptum esse: maledictus omnis, qui spem suam ponit in hominem.[...] et ideo hac ecclesiae potestate utimur, quam ei dominus et promisit et dedit).

55 Augustinus zieht den persischen König Nebudkadnezar als Typus des bekehrten Herrschers heran (vgl. Dan. 3.1-18). Dieses Exempel findet sich auch in den epp. 88, 93. 


\subsection{Rechtfertigung des Zwangs: Der Brief 93 an den Rogatisten Vincentius}

Als ausführlichstes Beispiel einer solchen Rechtfertigung ist die ep. 93 überliefert. Bischof Vincentius von Cartenna war das Oberhaupt einer kleinen donatistischen Abspaltung, die nach ihrem inzwischen verstorbenen Gründer Rogatus „Rogatisten“ genannt wurde ${ }^{56}$ Er hatte Augustinus als jungen Mann in Karthago kennen gelernt, vielleicht in ihrer Studentenzeit, ${ }^{57}$ und wandte sich nun um das Jahr 408 in einem Brief an den alten Bekannten, der nunmehr Bischof von Hippo war. Vincentius verurteilte die Gewaltanwendung infolge der antidonatistischen Gesetzgebung $(93.1,5)$ und verteidigte sein Verständnis von der Katholizität der Kirche, die seiner Ansicht nach nicht auf einer erzwungenen Einheit, sondern auf der strengen Beachtung der Gebote und der Reinheit der Sakramente beruhe (93.23). Zur Begründung seiner Ausführungen zog er neben der Heiligen Schrift auch Cyprian und Hilarius von Poitiers heran (93.21, 31-35). Obgleich Vincentius sich allgemein gegen die Verfolgung der Kirche wandte, wollte er im Besonderen erreichen, dass seine friedliche Glaubensgemeinschaft nicht durch die geltenden Gesetze unterdrückt oder gar zerstört werde. Vielleicht hoffte er, Augustinus dahingehend überzeugen zu kön-

56 Nur wenige Textstellen geben Auskunft über den Rogatismus. Ausgehend von ep. 93.12 spaltete sich Rogatus in Mauretania Caesariensis nach der Regierungszeit Julians mit einigen Kollegen von den Donatisten ab. Auslöser waren vermutlich Gewalttaten von Circumcellionen, von denen sich Rogatus distanzierte (ep. 93.11). Es ist ferner bekannt, dass die Donatisten die Rogatisten mit Hilfe des Firmus gewaltsam bekämpften (c. ep. Parm. I 16-17; c. litt. Pet. II 184; vgl. o. Kap. 2.1.1-2). Die Rogatisten, die die Donatisten entsprechend „Firmiani“ nannten (ep. 87.10), versuchten, vor römischen Gerichten ihren Besitz zu verteidigen (ep. 93.11). Die Gruppe war wohl niemals groß und hatte nur in Mauretanien Anhänger. Zur Zeit des Vincentius, dem Nachfolger des Rogatus, gab es laut Augustinus nur noch elf Mitglieder (ep. 93.20), dessen Aussage allerdings kaum wörtlich zu verstehen sein dürfte (gegen Willis, Augustine, 21). Zu den Personen und dem Rogatismus vgl. Mandouze, PAC, 990 f., s. v. Rogatus 5; 1208 f., s. v. Vincentius 2; Monceaux IV, $128 \mathrm{f}$; VI 315-318. - Vincentius ist nicht mit Vincentius Victor zu identifizieren, der in Augustins de natura et origine animae erwähnt wird. Vgl. die Belege bei Mandouze, PAC, $1173 \mathrm{f}$, s. v. Vincentius Victor 62 und Monceaux VI, 325-327, gegen Willis (Augustine, 31), der aufgrund dieser Identifizierung fälschlicherweise das Ende der Rogatisten auf 420 datiert. - Irreführend ist die Darstellung bei Frend (Donatist Church, 197), der Augustins ironische Darstellungen in ep. 93.11 und 49 wörtlich interpretiert und meint, Rogatus habe sich aufgrund der Trinkgelage der Circumcellionen mit neun Bischöfen abgespalten, um die traditionelle Reinheit aufrecht zu erhalten.

57 Ep. 93.1. Möglicherweise waren sie Studienfreunde (in den Jahren 370-373), möglich ist aber auch ein späterer Zeitpunkt, als Augustinus bereits Rhetoriklehrer war (374-383); vgl. Perler/Maier, 128-130. Kritisch gegenüber diesen Interpretationen äußert sich Vössing, Schule und Bildung, 294 f. mit Anm. 1085. 
nen, dass dieser seinen Einfluss darauf verwende, bei den Verantwortlichen Fürsprache für die Rogatisten einzulegen. ${ }^{58}$

Augustinus antwortete dem Rogatisten mit ep. 93, einer ausführlichen Darlegung seiner Position. ${ }^{59}$ Die Bildung seines Adressaten erklärt das gehobene Niveau und die Ausführlichkeit der Argumente, aber auch die zum Teil beißende Ironie gegen den Absolutheitsanspruch der rogatistischen Gruppierung (vgl. 93.21-26). Augustinus hatte jedoch nicht nur Vincentius im Blick, sondern auch andere Leser, denen seine Ausführungen helfen sollten (93.53). So verfasste er einen Traktat, in dem er erstmals grundlegend seine Haltung zur Zwangsgewalt darlegte und theologisch rechtfertigte. Zweifellos sollte diese Schrift als Handreichung und Information gerade für katholische Bischöfe und Kleriker dienen, die selbst oder für ihre Gläubigen den staatlichen Zwang gegen die Donatisten verteidigen mussten. ${ }^{60}$

Der Brief kann in zwei Hauptteile untergliedert werden: Der erste Teil (93.1-20) umfasst eine Apologie der Zwangsmaßnahmen gegen die Donatisten. Augustinus erklärt die Herausbildung seiner eigenen gegenwärtigen Position und die Gründe für seine Zustimmung zur coercitio. Seine Leser versucht er mit den bisherigen praktischen Erfolgen von Übertritten, durch geschichtliche Bezüge und mit biblischen Argumenten von seinem Standpunkt zu überzeugen. Der zweite Teil (93.20-53) beinhaltet eine Weiterführung der theologischen

58 Ein Versuch, Vincentius' Brief inhaltlich zu rekonstruieren, bei Monceaux VI, 318-322. Seine Interpretationen sind allerdings z. T. sehr spekulativ.

59 Edition: Goldbacher, CSEL 34.2, 445-496. Possidius (VI 9) verzeichnet mit contra epistulam Vincenti Donatistae et Rogatistae liber unus zweifellos ep. 93. Unter den epistulae findet sich die Angabe Vincentio una (VI 24). Hierbei handelt es sich wohl um eine Doublette; vgl. de Bruyne (RevBen 43, 307) und D. Ludwig (Indiculus, 94). - Zum Inhalt vgl. Monceaux VI, 322-324; E. Herzog, Ein Schreiben Augustins über kirchenpolitischen Zwang (Ep. 93), Internationale kirchliche Zeitschrift 6, 1916, 1-26; Grasmück, Coercitio, 214-219. - Datierung: terminus post quem ist Februar 405, terminus ante quem 411. Ep. 93, 17-18 spricht für einen Zeitpunkt, an dem die antidonatistischen Gesetze Auswirkungen zeigten. Vgl. Monceaux (VII, 132, 282), der den Brief um 408 datiert, und Goldbacher (CSEL 58, 28 f.) mit einer Datierung von 407/8 (gefolgt von Grasmück, 214 Anm. 267 und Mandouze, PAC, 1209). Augustins Ausführungen über die Konversionen sind allerdings rhetorisch zugespitzt und daher kaum zur sicheren Eingrenzung des Abfassungszeitraums geeignet. Wahrscheinlich bleibt jedoch eine Datierung zwischen 406 und 409.

60 Augustins Rechtfertigung der Zwangsgewalt (coercitio), die außer in ep. 93 insbesondere in ep. 185 aus dem Jahre 417 thematisiert wird, ist in der Forschung vielfach behandelt worden. Brown, Religion and Society, 260-278; Crespin, Ministère, 164-168; Grasmück, Coercitio, 205-240, zu ep. 93: 214-218; R. Joly, Augustin et la intolérance, Revue Belge de Philologie et d'Histoire 33, 1955, 263-294; Lamirande, AL 1, 1038 1046, s. v. Coercitio (mit weiterer Literatur), hier: 1041 f.; W. Geerlings, Foris inveniatur necessitas nascitur intus voluntas, Augustins Rechtfertigung des Zwangs, in: Universalität und Toleranz, Der Anspruch des christlichen Glaubens, Essen 1989, 41-47, hier: 43-46; Willis, Augustine, 127-135; K. H. Chelius, AL 1, 1084 f., s. v. Compelle intrare. 
Argumentation zu den Fragen des Schismas und eine Widerlegung der Argumente des Vincentius. Dabei stellt Augustinus besonders die paradoxe Situation der Rogatisten als Splittergruppe zwischen Donatisten und Katholiken heraus.

Zur Rechtfertigung der coercitio versucht Augustinus, ein auf christlicher Basis begründetes Verständnis zu formulieren: Es stelle sich nicht die Frage, ob die Anwendung von Zwang erlaubt sei, sondern welchem Ziel der Zwang diene. Die Furcht vor Sanktionen befreie die Menschen aus ihrem Irrtum und lasse sie für die Wahrheit offen werden, die sie dann freiwillig annehmen könnten (93.16). Augustinus verweist auf die vielen Menschen, die bereits zur katholischen Kirche zurückgekehrt seien $(93.1-2,17)$ und die in unterschiedlicher Weise bezeugen könnten, wie heilsam sich die Furcht vor den Gesetzen (legum timor) auf sie ausgewirkt habe. ${ }^{61}$ Wahrhaft verfolgt seien dagegen immer nur jene, die für eine gerechte Sache verfolgt würden (93.8).

Vincentius hatte die Einbindung des Staates in eine kirchliche Angelegenheit scharf kritisiert, da es seines Erachtens keine biblischen Vorbilder dafür gebe. In seiner Entgegnung weist Augustinus unter anderem darauf hin, dass Vincentius' Vorgänger Rogatus vor weltlichen Gerichten um den Besitz der Rogatisten gestritten habe (93.11). Ebenso seien die Donatisten nachweislich unter Berufung auf antihäretische Gesetze gegen Rogatisten und Maximianisten vorgegangen. Bereits zuvor hätten sich die Donatisten an Julian gewandt, um von diesem Apostaten und Götzendiener Hilfe zu erhalten (93.12). Auch die Klage der Donatisten gegen Caecilianus lasse klar erkennen, dass sie sich zuerst an den Kaiser gewandt hätten, dessen Urteil sie damals wie heute ablehnten (93.13-14, 19). ${ }^{62}$ Augustinus appelliert an Vincentius, die Gewalt der weltlichen Mächte (terror temporalium potestatum) als Mahnung zu verstehen und umzukehren (93.20).

Die Leitgedanken dieser Argumentation sind dieselben wie auch in ep. 105 an die donatistischen Laien: die Stilisierung der weltlichen Herrscher zu Verteidigern der christlichen Wahrheit und die Legitimierung der Zwangsgewalt in ihrer Funktion als „heilsamer Schrecken“. Allerdings verzichtet er gegenüber dem Rogatisten auf die Exempel der Gewalt, sondern zieht nur die historischen Beispiele heran, wohl wissend, dass von den Rogatisten keine Gewalt ausge-

61 Augustinus hält vor Augen, dass die einen aus ihrer Erstarrung, Trägheit und Tradition aufgerüttelt worden seien, andere hätten nur aufgrund der donatistischen Verleumdungen über die Katholiken keinen Übertritt gewagt. Viele freuten sich, durch die Gewaltandrohung neu nach der Wahrheit geforscht zu haben und zu neuen Erkenntnissen gekommen zu sein. Wieder andere hätten erst nach ihrem Übertritt erkannt, dass die donatistischen Vorhalte gegen die Katholiken Lügen gewesen seien, und wiederum andere hätten geglaubt, es sei egal welcher Kirche man angehöre; diese freuten sich nun über das Ende des Schismas (93.17-18). Trotz dieser Ausführungen war sich Augustinus der Tatsache bewusst, dass der Zwang auch Heuchelei verursachte.

Zur historischen Argumentation ausführlich u. Kap. 4.2.2. 
gangen war. Der Schwerpunkt liegt jedoch eindeutig auf den biblisch-theologischen Argumenten. Wie in ep. 105 bilden die Zitate aus der Heiligen Schrift und die damit verbundenen Beispiele die oberste Autorität.

Im zweiten Teil des Briefes bringt Augustinus seine ekklesiologischen Positionen zur Sprache: der Glaube an die weltweite Kirche Christi, die Vermischung von Sündern und Gerechten in einer Kirche und die Wiederaufnahme von Häretikern. Augustinus greift Vincentius scharf an und polemisiert gegen den Anspruch der Rogatisten, Alleinvertreter der Wahrheit zu sein (93.20-27). Augustinus legt einige Bibelstellen aus, um seine Vorstellung einer über die Welt verbreiteten Kirche, in der Sünder und Gerecht ihren Platz haben, zu untermauern und die exklusive Haltung der Rogatisten zu widerlegen (93.2835). In der Tauffrage argumentiert Augustinus ausführlich auf Grundlage von Cyprian und Tyconius, um Vincentius von der katholischen Sicht zu überzeugen (93.36-48). Schließlich appelliert Augustinus an seinen Adressaten, zurück in die katholische Kirche zu kommen. Er gesteht ein, dass es bei der Umsetzung von Zwangsmaßnahmen Missbrauch gegeben habe, doch sollten alle in der Kirche ertragen werden (93.50-53).

Diese Argumente des zweiten Briefteils entsprechen den Ausführungen, die in Augustins großen Abhandlungen begegnen. Hervorzuheben ist hier der Bezug auf Tyconius und die Erwähnung von Parmenians Schrift gegen diesen Theologen (93.43-44). Augustinus kannte zwar schon zu Beginn seines Episkopats Teile von Tyconius' Werk ${ }^{63}$ und setzte sich später in contra epistulam Parmeniani intensiv mit Parmenians Kritik an Tyconius auseinander, verzichtete jedoch in den antidonatistischen Schriften auf direkte Bezüge. ${ }^{64}$ Zweifellos, dies lässt Augustinus selbst anklingen (93.44), war der bei den Donatisten diskreditierte Tyconius keine Autorität, dessen Aussagen sich für eine Polemik gegen Donatisten eignete.

Der Brief zeigt eindrücklich Augustins Gratwanderung zwischen Verteidigung von Zwangsgewalt und christlicher Verkündigung. Augustinus hatte sich von den sichtbaren Ergebnissen überzeugen lassen und suchte erst danach einen theoretischen Überbau. ${ }^{65}$ Vincentius' Brief war die notwendige Herausforderung für ihn, erstmals eine Apologie ausführlich zu formulieren. Er ging schließlich einen Weg, die vorgegebenen Umstände theologisch-heilsgeschichtlich zu rechtfertigen. Sollte Vincentius tatsächlich geglaubt haben, Augustinus würde ausgehend von der Heiligen Schrift und Cyprian in der Frage der

63 In ep. 41.2 an Aurelius (Bischof von Karthago) erwähnt Augustinus Tyconius' Liber Regularum und erbittet Aurelius' Meinung dazu.

64 Ausnahme ist ep. 249 an den Diakon Restitutus, den Augustinus zur Lektüre von Tyconius auffordert, aber auch auf Probleme und Differenzen hinweist. Zu Tyconius vgl. o. Kap. 2.1.2.

65 Im gleichen Sinne: Geerlings, Augustins Rechtfertigung, $43 \mathrm{f}$. 
Zwangsgewalt seinem Verständnis der Gewaltlosigkeit zustimmen, so hatte er sich getäuscht. $\mathrm{Ob}$ Augustinus mit seinem Sarkasmus und den Appellen an die Vernunft die augenscheinliche Realitätsferne des Rogatisten zu durchbrechen vermochte, darf bezweifelt werden.

\subsection{Widerstand gegen Donatisten: Die Briefe 53 und 89 an Katholiken}

Seine katholischen Briefpartner musste Augustinus grundsätzlich nicht davon überzeugen, dass Donatisten aus seiner Sicht falsche Ansichten vertraten. Entsprechend fehlen in den meisten Briefen an Katholiken längere antidonatistische Argumentationen und Polemiken. Die Briefe an Generosus (ep. 53) und Festus (ep. 89) stellen diesbezüglich Ausnahmen dar. In beiden Fällen wollte Augustinus den Adressaten Unterstützung in ihrem Widerstand bzw. Kampf gegen Donatisten zukommen lassen. Mit seinen Argumenten sollten sie eine Grundlage erhalten, um sich der Auseinandersetzung mit Donatisten zu stellen. $^{66}$

Augustinus schrieb ep. 53 um das Jahr 400 zusammen mit den Bischöfen Alypius von Thagaste und Fortunatus von Cirta an einen nicht weiter bekannten katholischen Gläubigen aus Cirta namens Generosus. ${ }^{67}$ Dieser hatte von einem donatistischen Priester einen Brief erhalten, in dem er unter Berufung auf eine Engelserscheinung aufgefordert wurde, sich der donatistischen Gemeinde anzuschließen. Generosus ließ sich jedoch nicht darauf ein, sondern leitete den Brief des Donatisten an die drei genannten Bischöfe weiter, die sowohl für ihn als auch für jenen donatistischen Priester eine Antwort schickten (53.1).

Die Absender geben Generosus einige Ratschläge: Sie weisen auf die biblische Vorhersage der weltweiten Ausbreitung der Kirche hin, die im Widerspruch zu dem auf Afrika beschränkten Donatismus stehe (53.1). Da in dem

66 Vgl. für die Zeit um 400 auch epp. 56, 57: Augustinus übergab dem Laien Celer, der mit dem Donatismus sympathisierte, einen codex zum Lesen (vermutlich einen oder mehrere seiner antidonatistischen Traktate, ep. 57.1) und beauftragte die jeweils überbringenden Priester, weitere Fragen zu beantworten (56.1, 57.2). Vgl. Mandouze, PAC, 202 f., s. v. Celer 1.

67 Edition: Goldbacher, CSEL 34.2, 152-158. Vgl. Poss. indic. X ${ }^{5}$ 40. Zum Inhalt: Monceaux VI, $305 \mathrm{f}$. - Datierung: In ep. 53.3 wird als gegenwärtiger römischer Bischof Anastasius genannt (399-401), so dass der Brief um das Jahr 400 zu datieren ist. Vgl. Monceaux VI, 305; VII, 131 f., 280; Mandouze, PAC, 532. Perler/Maier (230-232) folgern aus ep. 53 eine Reise Augustins und Alypius' nach Cirta im Jahre 400. Goldbacher (CSEL 58, 18) nimmt fälschlicherweise das Jahr 398 als Pontifikatsbeginn des Anastasius an und bestimmt als terminus ante quem den Tod des Praetextatus (vgl. 53.6), den er auf 400 datiert. Dieses Datum ist jedoch nicht zu halten. - Zu Generosus: Mandouze, PAC, 532 f., s. v. Generosus 1. Möglicherweise ist er mit dem gleichnamigen Konsular zu identifizieren, der in epp. 115/116 erwähnt wird. 
Brief der Donatisten an Generosus mit der Sukzession der Bischöfe von Cirta argumentiert worden war (53.1), zählen sie die Reihe aller römischen Bischöfe von Petrus bis Athanasius auf, um die Apostolizität der katholischen Kirche zu demonstrieren. Sie fügen hinzu, dass kein Traditor in den Reihen der Bischöfe die gesamte Kirche verunreinige (53.2-3). Damit Generosus nachweisen könne, wie unrecht die Donatisten selbst gehandelt hätten, dass sie sogar Traditoren in ihren Reihen geduldet hätten, empfehlen ihm die drei katholischen Bischöfe die Zuhilfenahme von historischen Dokumenten, die er den Gegnern vorlesen solle (53.4-5). Ebenso diene der Hinweis auf die Wiederaufnahme der Maximianisten Praetextatus und Felicianus nach ihrer Verurteilung zur Darstellung der donatistischen Inkonsequenz. Die Heilige Schrift schließlich bezeuge, dass in der weltweiten Kirche Gute und Schlechte ihren Platz hätten und diese Kirche niemals von irgendwelchen Schandtaten in Afrika befleckt werden könne (53.6-7).

Die Argumente, die Generosus hier an die Hand bekam und im Dialog anwenden sollte, entsprechen dem Katalog an Argumenten, mit denen Augustinus selbst seine Gespräche und Schriften vor dem Jahr 405 bestritt. Die Versatzstücke tauchen in ähnlicher Form in den epp. 34, 44 und 76 auf, ebenso wie in den Büchern gegen Petilianus. Durch den besonderen Anlass bedingt war lediglich die Aufzählung der römischen Bischöfe zum Nachweis der wahren Apostolizität und die Hervorhebung der causa Silvani.

Mit ep. 89 an Festus richtete sich Augustinus in der Zeit nach dem Einheitsgesetz von 405 an einen römischen Beamten, der mit der Durchführung der antidonatistischen Gesetze beauftragt worden war. ${ }^{68}$ Anlass des Briefes war die Bitte an Festus um konkrete Unterstützung im Kampf gegen die Donatisten von Hippo Regius. Die Durchsetzung der Gesetze gegen die Donatisten in Hippo war bisher an den Verantwortlichen gescheitert, weil sie angeblich selbst Donatisten gewesen seien. Festus sollte deshalb einen seiner Vertrauten nach Hippo schicken, um zunächst vertraulich Augustinus zu konsultieren, damit über das weitere Vorgehen beraten werden könne (89.8). Augustinus nutzte den Anlass, um einerseits Festus selbst über seine Beweggründe zu informieren, andererseits ihm Argumente an die Hand zu geben, mit denen er jene über-

68 Edition: Goldbacher, CSEL 34.2, 419-425. Vgl. Poss. indic. VI 33. Zum Inhalt vgl. Monceaux VII, 137, 140 f.; Grasmück, Coercitio, 205 f. - Datierung: Der Brief muss einige Zeit nach Verkündung des Unionsgesetzes verfasst worden sein. Monceaux (VII, 132, 282) datiert um 406; Goldbacher (CSEL 58, 27) legt sich nicht genauer fest. Insbesondere die historische Argumentation zeigt die Nähe zu epp. 88, 93, 105. Wahrscheinlich ist daher eine Abfassung um 406/7. - Auf den Rang des Adressaten deuten die Anrede (domino dilectissimo et honorabili ac suscipiendo filio Festo) sowie die Anspielungen im Text, vor allem ep. 89.8. Zur Person: Mandouze, PAC, 451, s. v. Festus 1; PLRE II, 466 f., s. v. Festus 1. 
zeugen könne, die die Zwangsmaßnahmen ablehnten oder behinderten (89.8). Augustinus hatte offenbar die Erfahrung gemacht, dass viele Beamte wenig Interesse an der Umsetzung der Gesetze gegen die Donatisten bekundeten oder sich sogar gegen die Anwendung der Gewalt aussprachen. Viele verstanden nicht, warum sie mit solch strengen Strafen gegen die Anhänger der Donatisten vorgehen sollten, obwohl sie keinen Unterschied zum Kult der Katholiken erkannten. Augustinus wollte entsprechend über den historischen und theologischen Hintergrund der Gesetzgebung informieren und die Notwendigkeit der strengen Durchsetzung der Maßnahmen begründen. ${ }^{69}$

Der Brief enthält eine kurze Darstellung der wichtigsten Argumente für die Zwangsmaßnahmen gegen die Donatisten. Im Gegensatz zu den an Donatisten gerichteten epp. 88 und 105 steht nicht die Aufzählung einzelner Gewalttaten im Vordergrund, sondern eine allgemeine Beurteilung des donatistischen Verhaltens und die Konsequenzen, die daraus zu ziehen seien. Die Donatisten, so Augustinus, verharrten in Irrtum und Schisma und wehrten sich nicht nur gegen die Berichtigung ihrer Fehler, sondern verdrehten noch die Tatsachen, indem sie sich rühmten, Opfer der Verfolgung zu sein, obwohl sie selbst die wahren Verfolger seien. Nach einem Abriss über die Entstehung des Schismas (89.3-4) erläutert Augustinus die Unterschiede des katholischen und donatistischen Taufverständnisses (89.5) sowie Absicht und Ziel der Zwangsmaßnahmen aus kirchlicher Sicht (89.6-7): Die Kirche und die weltlichen Gewalten seien lediglich in der Lage, den Weg zu bereiten, sei es mit Worten, sei es mit Zwang, die tatsächliche Veränderung müsse aber Gott überlassen werden.

Die Briefe 53 und 89 zeigen sehr deutlich die zwei Seiten des augustinischen Kampfes gegen die Donatisten: Auf der einen Seite die persuasio, die Überzeugungsarbeit auf Grundlage von Argumenten und Dokumenten, auf der anderen Seite die coercitio, die Anwendung des Zwanges gegen donatistische Gewalt und die Trägheit der Gewohnheit. Ep. 89 ist ferner ein Beispiel dafür, wie die katholisch-donatistischen Differenzen bei den Laien in Afrika auf Unverständnis stießen.

\section{Die historische Argumentation}

\subsection{Die Briefe vor dem Unionsgesetz von 405 (epp. 43, 53, 76)}

In den Briefen Augustins aus den Jahren vor 405 finden sich die ausführlichsten Darstellungen historischer Argumentation in den epp. 53 und 76, in denen jeweils die Entstehung des Schismas referiert wird, sowie in ep. 43 mit der Re-

69 Vgl. ep. 86 an Caecilianus und ep. 97 an den MO Olympius, in denen Augustinus zur Durchsetzung der Gesetze ermahnt. 
flexion des Gesprächs zwischen Augustinus und den donatistischen Laien. ${ }^{70}$ Gegenüber seinen donatistischen Bischofskollegen verweilt Augustinus wesentlich länger bei theologischen Erörterungen, insbesondere in der Frage des Rechts und Unrechts von Verfolgung. Gerne greift er hier zum Vergleich mit dem Maximianistischen Schisma, um die donatistische Sakramentenlehre anzugreifen. Der Disput Augustins mit Fortunius in Thubursicum Numidarum (ep. 44), seine Briefe an Emeritus (ep. 87), Honoratus (ep. 49) und Crispinus von Calama (ep. 51) bezeugen diese Akzentsetzung und stehen diesbezüglich in enger Bindung zur Argumentation in den Büchern gegen Petilianus. Die historische Argumentation wird dagegen nachrangig behandelt. So wird im Gespräch mit Fortunius deutlich, dass zunächst andere Themen angesprochen und diskutiert wurden und am Ende die Zeit nicht mehr reichte, die Geschichte des Schismas eingehender zu erörtern (vgl. 44.5, 12). Auch gegenüber Emeritus spricht Augustinus davon, bei einer Fortsetzung der Gespräche über die Ursachen des Schismas zu diskutieren (87.10). Gegenüber den Laien verzichtete Augustinus weitgehend auf die schwierigen theologischen Fragen. In der Geschichte des Donatismus sah er jedoch ein Instrument, die aus seiner Sicht falschen Ansichten der Donatisten anschaulich zu widerlegen.

Ebenso wie in den Büchern gegen Cresconius stellt Augustinus in den Briefen die Anfänge des Schismas dar, um die Schuldfrage der Kirchenspaltung zu klären. Die Essenz der historischen Argumentation findet sich in dem Traktat ep. 76. Im Verlauf weniger Sätze streift Augustinus die entscheidenden Stationen der causa Caeciliani und lässt sie in einem Appell zur Einheit münden:

„Einige von euren Vorfahren, in deren gottloser Abspaltung ihr verharrt, haben nämlich nach Ausweis städtischer Akten die heiligen Kodizes und Gegenstände der Kirche den Verfolgern ausgehändigt. Andere haben geständige [Traditoren] freigesprochen und mit ihnen Kirchengemeinschaft gepflegt. Beide Gruppen kamen in Karthago zu wütenden Umtrieben zusammen; sie verurteilten aufgrund des Vergehens der traditio andere [Bischöfe] ohne Anhörung, über die sie sich selbst zuvor abgestimmt hatten, und ordinierten Bischof gegen Bischof und errichteten Altar gegen Altar. Später schickten sie einen Brief an Kaiser Konstantin, damit Bischöfe aus Übersee zwischen den Afrikanern urteilen sollten. Den bestellten Richtern, die sie gefordert hatten und die in Rom ein Urteil sprachen, folgten sie nicht; sie klagten die Bischöfe beim Kaiser an, als ob sie schlecht geurteilt hätten; und von anderen Bischöfen, die nach Arles geschickt worden waren, appellierten sie wiederum an den Kaiser. Vom Kaiser selbst verhört und für Verleumder befunden, verharrten sie im gleichen Frevel. Erwachet zum Heil, liebet den Frieden, kehret

70 Ein kurzer Hinweis auf die bischöflichen Urteile über Caecilianus findet sich auch in ep. 52.2 an den donatistischen Laien Severinus, geschrieben wahrscheinlich um 400 (vgl. Monceaux VII, 280). 
um zur Einheit! Wenn ihr wollt, lesen wir euch dies alles vor, auf welche Weise das geschehen ist. “71

Augustinus beginnt diese Aufzählung mit seinen Kenntnissen über die traditio in Cirta und das spätere Konzil von Cirta, stellt dann den Zusammenhang zwischen den Traditoren von Cirta und dem Konzil von Karthago her. Ohne die Namen zu nennen, spricht er von der Unrechtmäßigkeit der Verurteilung Caecilians und anderer Bischöfe, die zum Schisma geführt habe. Schließlich belege das Urteil des Kaisers endgültig die Schuld der Donatisten, nachdem sie die bischöflichen Urteile nicht hätten akzeptieren wollen.

Im Brief an Generosus finden sich die gleichen Bausteine wieder. Augustins Ausführungen sind hier nicht in einem Referat über die Geschichte des Schismas zusammengefasst, sondern erschöpfen sich in einer Anweisung an Generosus, mit welchen Dokumenten er gegen die Donatisten argumentieren könne. Augustinus beginnt mit den Akten zu den Ereignissen aus Generosus' Heimatstadt Cirta. Wie im ersten Buch gegen Petilianus (c. litt. Pet. I 23) will Augustinus demonstrieren, dass sich gerade in Cirta Traditoren unter den Vorgängern des gegenwärtigen Bischofs Petilianus befunden hätten. Er weist Generosus auf die acta Munati Felicis hin, mit denen die traditio des Silvanus von Cirta, der in der donatistischen Bischofsliste genannt worden war, erwiesen werden könne. Aus dem Protokoll von Cirta zitiert Augustinus die Namen jener geständigen Traditoren, die zusammen mit Secundus von Tigisi Silvanus geweiht hätten, und nennt den Versammlungsort, das Haus des Urbanus Donatus. Möglicherweise rechnet Augustinus damit, dass Generosus mit dieser Angabe etwas anfangen kann, und durch eine genaue Identifizierung des Ortes seiner Darstellung mehr Glaubwürdigkeit verliehen wird. Schließlich weist er noch auf die gesta apud Zenophilum, in denen die Schuld des Silvanus ganz klar werde (53.4).

Nach diesen Hinweisen zu Silvanus ergänzt Augustinus summarisch die Prozessfolge gegen Caecilianus und macht Generosus wiederum auf Dokumente aufmerksam, in denen die Ereignisse und Urteile bezeugt seien: Die

71 Ep. 76.2: maiores enim uestri, in quorum sacrilega praecisione perseueratis, quidam gestis municipalibus codices sanctos et instrumenta ecclesiae persecutoribus tradiderunt, quidam eos fatentes dimiserunt et eis communicauerunt et utrique Carthaginem furiosa factione conuenerunt, de crimine traditionis, de quo ipsi inter se iam consenserant, inauditos damnauerunt, episcopum contra episcopum ordinauerunt, altare contra altare erexerunt. postea litteras ad imperatorem Constantinum, ut inter Afros episcopi transmarini iudicarent, miserunt; datis iudicibus, quos postulauerant, et Romae iudicantibus non obtemperauerunt; episcopos apud imperatorem, tamquam male iudicauerint, arguerunt; ab aliis rursus episcopis ad Arelatum missis ad ipsum imperatorem appellauerunt; ab ipso auditi et calumniatores inuenti in eodem scelere permanserunt. euigilate ad salutem, amate pacem, redite ad unitatem. haec uobis, quem ad modum gesta sint, quando uultis, omnia recitamus. 
preces der Donatisten an Konstantin, einen Brief des Kaisers zur Ladung der Bischöfe nach Rom, die römischen Konzilsakten sowie einen weiteren Brief Konstantins, in dem die Appelle der Donatisten, der Entschluss zum Konzil von Arles und der kaiserliche Entscheid über die Unschuld Caecilians nachzulesen seien. ${ }^{72}$ Auf eine weitergehende Interpretation der historischen Dokumente verzichten Augustinus und seine Mitverfasser. Die Aussagen dieser Zeugnisse sollten genügen, um die Argumente des donatistischen Priesters zu widerlegen, und es sollte Generosus überlassen bleiben, wie er mit diesen Hinweisen weiter verfahre.

Welche Möglichkeit zur Interpretation jene Quellen bieten konnten, die er Generosus zur Beweisführung vorschlägt, demonstriert Augustinus selbst in seiner ep. 43 an die Laien von Thubursicum Numidarum. Ausgangspunkt der gesamten Argumentation, sowohl im persönlichen Gespräch als auch in seinem Brief, war die These der Donatisten, dass die causa Caeciliani durch das Urteil der siebzig Bischöfe in Karthago unter der Führung des Secundus von Tigisi endgültig entschieden worden sei. Die donatistischen Gesprächsteilnehmer hatten die Konzilsakten mit den Verdammungssentenzen präsentiert und erwarteten von Augustinus eine Antwort auf die Frage, warum dieses eindeutige Urteil von den Katholiken nicht akzeptiert werde. Augustinus greift nun auf seine eigenen Dokumente zurück, um auf dieser Grundlage zu antworten und die These der Donatisten zu entkräften. Der Aufbau seiner Argumentation in

72 Ep. 53.5. - Das hier an zweiter Stelle genannte Schreiben ist zweifellos der Brief Konstantins an Eumalius. Der an erster Stelle genannte Brief ist schwieriger zuzuordnen (litteras etiam eiusdem imperatoris, ubi episcopos misit ad urbem Romam). Handelt es sich dabei um den Brief an Miltiades und Marcus, der bei Eusebius (HE X 5.18-20) überliefert ist? Dieser Brief scheint auf der Konferenz von 411 vorgelegen zu haben (breuic. III 24: tum deinde lectae sunt etiam litterae supradicti imperatoris [Constantini] ad episcopos datae, ubi eis causam Caeciliani iniunxit audiendam). Anhand dieser Formulierung könnte man auch vermuten, dass Augustinus nicht von einem Brief an Miltiades, sondern an mehrere Bischöfe spricht, und damit womöglich jenen Brief meint, durch den nach Konstantins eigenen Worten die gallischen Bischöfe nach Rom beordert wurden. Jedoch geht aus Cap. conl. Carth. III 318 klar hervor, dass der herangezogene Brief jener an Miltiades war. Dass Augustinus den Brief kannte, wird zudem in s. Denis 19.8 deutlich. Möglicherweise bezieht sich dennoch die Anspielung von ep. 53.5 nicht auf den Brief an Miltiades, sondern auf die in diesem Schreiben erwähnte Einberufung an die gallischen Bischöfe Reticius, Maternus und Marinus (vgl. Lancel, SC 194, 92 Anm. 2). Doch ist dies wenig wahrscheinlich: Warum sollte Augustinus ausgerechnet gegenüber seinem Adressaten Generosus auf ein Dokument hinweisen, das in der gesamten Auseinandersetzung nie wieder auftaucht, folglich nicht leicht zugänglich oder überhaupt nicht vorhanden war? Der Brief an Miltiades gehörte dagegen zur Aktensammlung der karthagischen Konferenz. Augustinus weist also mit hoher Wahrscheinlichkeit in ep. 53 auf den Brief Konstantins an Miltiades hin, der offensichtlich in mehrfachen Abschriften zur Verfügung stand. 
ep. 43 entspricht weitgehend der angegebenen Reihenfolge der im Gespräch vorgelesenen Dokumente (43.5). Von den jeweiligen Zeugnissen ausgehend entfaltet Augustinus seine Analysen und Schlussfolgerungen, jedoch stets mit Bezug auf die zu widerlegende These. ${ }^{73}$ An einigen Stellen bezieht sich $\mathrm{Au}-$ gustinus auf Einwände und Kritiken, die während des Gesprächs gefallen waren (43.10, 12-13), immer wieder macht er seine Adressaten auf die ihnen bereits bekannten Dokumente aufmerksam (43.14-15, 17, 20). Aufgrund der parallelen Abhandlung der Dokumente und den häufigen Bezugnahmen auf das Gespräch lässt sich davon ausgehen, dass die Ausführungen in ep. 43 weitgehend den Argumenten entsprechen, die Augustinus bereits mündlich vorgebracht hatte.

Zum besseren Verständnis der Argumentation Augustins ist es hilfreich, einige Grundanlagen der Struktur im Voraus $\mathrm{zu}$ verdeutlichen: Augustinus wertet die ihm vorliegenden historischen Dokumente stets mit dem Ziel aus, die donatistische These einer Verurteilung Caecilians in Karthago zu widerlegen. Gleichsam in der Funktion eines Verteidigers Caecilians sucht Augustinus in ihnen Beweise, um das Urteil der siebzig Bischöfe gegen Caecilianus als unrechtmäßig darzustellen. Dazu analysiert er das Motiv der Ankläger, die Zuständigkeit des Gerichts, die Integrität der Richter, die Beweise der Anklage und die Rechtmäßigkeit des Verfahrens. Zudem verteidigt er die Legitimität der Prozesse in Rom und Arles sowie das Handeln des Kaisers. Mit Hilfe zahlreicher Gegenüberstellungen polarisiert Augustinus Recht und Unrecht in den jeweiligen Verfahren. $\mathrm{Zu}$ den wichtigsten Gegenüberstellungen gehört zum einen der Vergleich der Entscheidung von Cirta mit der Entscheidung von Karthago, zum anderen der Vergleich der römischen mit der karthagischen Synode. Weitere Gegenüberstellungen sind auch aus anderen Texten Augustins bekannt, wie die Verurteilung Caecilians in Abwesenheit und ohne Anhörung im Gegensatz zu seinem Freispruch in Anwesenheit, oder der Gegensatz zwischen der Bedeutungslosigkeit des afrikanischen Streites im Verhältnis zur weltweiten Christenheit.

Augustins Quelleninterpretationen werden auf Grundlage dieses Argumentationsrahmens verständlich: Er beginnt mit dem Protokoll von Cirta und der Rolle des Secundus von Tigisi in Gegenüberstellung zum Konzil von Karthago (43.6-11), es folgt die Auswertung der acta purgationis Felicis zur Klärung der Schuldfrage (43.12-13), anschließend die Interpretation des Konzils in Rom auf Grundlage der Konzilsakten sowie der preces der Donatisten an den Kaiser und einem Brief Konstantins (14-18). In Ergänzung zu diesen Akten verweist

73 Monceaux (VI, 298) erwähnt die ausführliche Quellenkommentierung Augustins und zählt die wichtigsten Themen auf. Lamirande (Studia canonica 32, 1998, 214 f.) betont Augustins sorgfältige Dokumentation als Antwort auf die donatistischen Konzilsakten von 312, Beide verzichten jedoch darauf, die gezielte Interpretation der Quellen durch Augustinus näher zu beleuchten. 
er auch auf die gesta apud Zenophilum (43.17), die während des Gesprächs in Thubursicum nicht vorgelesen worden waren. Den Abschluss bildet eine erneute Rechtfertigung der bischöflichen Urteile von Rom und Arles sowie der Rolle des Kaisers in diesem Verfahren (43.19-20).

Zur Einführung in die Auseinandersetzung mit der causa Caeciliani hält Augustinus seinen Adressaten vor Augen, dass die historischen Zeugnisse eine eindeutige und klare Sprache sprächen: Obwohl eine ansehnliche Zahl von siebzig Bischöfen ein Urteil gesprochen habe, so bewiesen dennoch genügend Dokumente, dass dieses Urteil unrechtmäßig zustande gekommen sei, denn der Angeklagte sei nicht vor der Synode erschienen; außerdem hätten sich geständige Traditoren unter den Richtern befunden (43.6). Zum Nachweis interpretiert Augustinus das Protokoll von Cirta, wobei er sich auf die Person des Secundus von Tigisi konzentriert. Er lenkt die Aufmerksamkeit auf die Motivation des Secundus und dessen Verantwortung für die Vorgänge in Karthago. Ihm wirft er vor, aus persönlichem Interesse gehandelt zu haben, ohne Rücksicht auf die Folgen für die Kirche. Wie später gegen Cresconius kritisiert Augustinus keineswegs die Toleranz des Secundus gegenüber den geständigen Traditoren von Cirta, sondern ausdrücklich den Widerspruch zwischen dem Urteil in Cirta und dem Urteil in Karthago. Er verurteilt das Verhalten, das schließlich zum Verrat an der kirchlichen Einheit geführt habe. ${ }^{74}$

Das Scheitern einer Einigung begründet Augustinus ferner mit der fehlenden Rücksichtnahme auf die weltweite Kirchengemeinschaft. Secundus und seine Mitstreiter hätten beachten müssen, dass sich Caecilianus und die mitangeklagten Bischöfe aufgrund ihres Ranges an ein Gericht anderer Kollegen der apostolischen Kirche hätten wenden können. Doch in Kenntnis ihrer eigenen Vergehen und der Verfahrensfehler in Karthago hätten sie dies missachtet, wohl wissend, dass sie mangels Beweisen gegen die Angeklagten vor einem überseeischen Gericht nicht bestehen würden (43.9). Caecilianus jedoch sei sich dieser Möglichkeit sehr wohl bewusst gewesen und habe recht entschieden, nicht am Versammlungsort seiner Gegner zu erscheinen $(43.7-11) \cdot{ }^{75}$ Rhetorisch verpackt in einer „Friedensrede“, die er Secundus in den Mund legt, demon-

74 Secundus habe namentlich bekannten Traditoren verziehen, gleichzeitig werde durch die Anschuldigungen des Purpurius von Liniata klar, dass Secundus sich selbst der traditio schuldig gemacht habe. Er habe nicht um des Friedens, sondern um seiner selbst willen, aus Furcht vor der Offenlegung seiner Schuld, die ganz offenkundigen Vergehen der Bischöfe dem Urteil Gottes überlassen $(43.3,6)$. Dieses eigennützige Handeln bestätige sich durch das Verhalten in Karthago, wo Secundus mit Hilfe von geständigen Traditoren die traditio verurteilt habe, trotz Abwesenheit der Beklagten und mangelndem Erweis ihrer Schuld (43.7, 10-11). Zum Inhalt des Protokolls von Cirta vgl. auch o. Kap. 3.4.2.1.

75 Caecilianus hatte der Vorladung vor das Konzil des Secundus in Karthago keine Folge geleistet, vgl. Opt. I 19. 
striert Augustinus, auf welche Weise das Schisma hätte verhindert werden können (43.8): Geständige Traditoren hätten entweder dem Urteil Gottes überlassen oder aber vor Bischöfen anderer Kirchenprovinzen angeklagt werden sollen, wenn sich gegen die erste Lösung Widerspruch geregt hätte. Auch im Falle Caecilians hätte erst die Gemeinschaft aller Christen den Streit klären müssen, ehe es zur Wahl eines anderen Bischofs hätte kommen dürfen. Denn eigenmächtiges Handeln provoziere die Spaltung der Kirchen.

Beachtenswert sind an dieser Stelle die zwei Alternativen für den Umgang mit Traditoren, die Augustinus als gangbar und den Frieden erhaltend vorstellt. Zum einen akzeptiert er hier die Anrufung eines iudicium dei, wie sie in Cirta von Secundus durchgeführt wurde. Zum anderen plädiert er für die Austragung der Streitigkeiten vor unabhängigen Bischöfen anderer Provinzen und präsentiert so die Catholica als Schlichtungsinstanz für Auseinandersetzungen der afrikanischen Kirche. Beide Alternativen sind an dieser Stelle der Argumentation taktisch motiviert. Es kam Augustinus in erster Linie darauf an, die ungleiche Behandlung der Traditoren in Cirta und der vermeintlichen Traditoren in Karthago herauszustellen. Tatsächlich ist die Vorstellung anachronistisch, von einer bischöflichen Appellationsmöglichkeit an Kollegen anderer Provinzen auszugehen. ${ }^{76}$ Caecilians Motiv, das Konzil von Karthago abzulehnen, bestand folglich nicht in der Hoffnung, in Europa ein faires Urteil zu erhalten, wie Augustinus es seinen Lesern einreden wollte. Vermutlich glaubte Augustinus sogar, dass kirchenrechtlich ein europäisches Konzil in afrikanischen Angelegenheiten entscheiden durfte. Doch spielt seine eigene Überzeugung hier nur eine untergeordnete Rolle. Entscheidend ist Augustins Absicht, einerseits den später tatsächlich erfolgten Freispruch Caecilians durch ein iudicium transmarinum $\mathrm{zu}$ rechtfertigen und bereits in Vorausschau als selbstverständliche Instanz zur Wahrung des Kirchenfriedens zu etablieren, zum anderen auch an dieser Stelle die Notwendigkeit einer gesamtkirchlichen Perspektive darzustellen, die er den Donatisten grundsätzlich absprach. In seiner Interpretation des Entscheidungsablaufs von Karthago 312 verurteilte Augustinus insofern Verstöße der Donatisten gegen ein kirchliches Recht, das der Präzedenzfall Caecilianus erst schaffen sollte.

Nachdem er Ankläger und Richter des Konzils von Karthago abqualifiziert hat, wendet sich Augustinus der Überprüfung der Beweise der Anklage zu. Zentrale Frage war die Schuld des Felix von Abthugni. Während die Donatisten daran festhielten, dass Felix Traditor gewesen und deshalb die Weihe Caecilians zu Recht nicht anerkannt worden sei, verweist Augustinus auf die fehlenden Beweise für diese Anklage. Die Akten aus Karthago gäben keinen Hinweis, woher die Anklage ihre traditio-Anschuldigung genommen habe, und Felix selbst sei 
schließlich nicht verhört worden. Später jedoch, in dem Verfahren vor dem Prokonsul Aelianus, sei Felix nach einer sorgfältigen Untersuchung freigesprochen worden, wie die prokonsularischen Protokolle bewiesen (43.12). Einer der donatistischen Gesprächsteilnehmer in Thubursicum hatte diesen Beweis abgelehnt und angemerkt, dass ein Bischof nicht durch das Urteil eines Prokonsuls gerechtfertigt werden solle. Außerdem hatte er kritisiert, dass während des Verfahrens die Folter gegen Ingentius angewandt worden sei (43.13). Auch wenn diese Aussagen laut Augustinus das Missfallen anderer Gesprächsteilnehmer erregten, so sind sie dennoch bezeichnend für das grundsätzliche Kirchenverständnis der Donatisten. Felix war der traditio angeklagt und nach donatistischer Auffassung rechtmäßig und unwiderruflich durch ein Konzil verurteilt worden; der Freispruch durch ein weltliches Gericht besaß für sie keine Gültigkeit. Dass dieser Freispruch zudem durch das peinliche Verhör des Hauptbelastungszeugen zustande gekommen sei, bestätigte in den Augen des Donatisten in Thubursicum obendrein die Verwerflichkeit dieses Vorgehens. ${ }^{77}$

Augustinus geht auf die beiden Einwände ein und verteidigt den Prozess vor einem weltlichen Gericht, indem er auf die Klage der Donatisten beim Kaiser hinweist, mit der sie schließlich als erste den Fall seiner Sorge unterstellt hätten: „Wenn es aber kein Verbrechen ist an den Kaiser zu appellieren, dann ist es auch kein Verbrechen, vom Kaiser verhört zu werden oder von jenem, an den der Kaiser den Fall übertragen hat. ${ }^{\text {"78 }}$ Dem zweiten Einwand weicht Augustinus aus und verweist auf die Verantwortung des Prokonsuls für die Methode des Verhörs. Felix hätte nicht eingreifen können, ohne sich damit schuldig zu bekennen. Augustinus betont zudem, dass auch der Prokonsul niemals einen Abwesenden verurteilt hätte und schlägt damit nochmals einen Bogen zur Unrechtmäßigkeit des Verfahrens in Karthago im Gegensatz zur rechtmäßigen Durchführung des Verfahrens gegen Felix von Abthugni (43.13).

Nach der Gegenüberstellung der Konzile von Cirta und Karthago mit der Ergänzung um die causa Felicis beleuchtet Augustinus das Verfahren gegen Caecilianus aus einer weiteren Perspektive, indem er die Akten der Synode von Rom auswertet und der Entscheidung von Karthago gegenüberstellt (43.14-18). Zunächst verteidigt Augustinus das rechtmäßige Zustandekommen der römischen Synode unter Miltiades mit dem Hinweis auf das Bittgesuch der Donatisten und dem Brief des Kaisers. Daraus gehe klar hervor, dass der Kaiser auf

77 Die Aussage ist freilich nicht ganz richtig. Den acta purgationis Felicis (Opt. App. II 10) gemäß wurde Ingentius die Folter lediglich angedroht. Vgl. u. Kap. 6.1.3. Vgl. Girardet (Kaisergericht, 10-17) zum altkirchlichen Verständnis bei Streitigkeiten zwischen Christen: Vor einem weltlichen Gericht sollte keine Anklage erfolgen.

78 Ep. 43.13: Si autem criminis non est prouocare ad imperatorem, non est criminis audiri ab imperatore, ergo nec ab illo, cui causam delegauerit imperator. 
Wunsch der Donatisten die richterliche Untersuchung durch den römischen Bischof und dessen Kollegen angeordnet habe. Schon aus diesem Grund sei es kein Unrecht des Miltiades gewesen, das Verfahren nach dem Urteil der siebzig Bischöfe von Karthago an sich zu ziehen (43.14).

Anschließend erläutert Augustinus seinen Adressaten, was sich aus dem Protokoll der Verhandlungen in Rom ergebe: Die Untersuchung sei sorgfältig erfolgt mit der Absicht, den Frieden und die Einheit der Kirche zu bewahren und wiederherzustellen. Es sei festgestellt worden, dass die Ankläger und ihre Zeugen die Anschuldigungen gegen Caecilianus nicht hätten begründen können. Stattdessen hätten sie auf die Anhänger der Partei des Maiorinus im Kirchenvolk verwiesen. Dies bedeute also, folgert Augustinus, dass die Anklage auf eine aufgebrachte und dem Frieden feindliche Volksmenge zurückgehe; allein der Tumult und das Geschrei des Pöbels, die Beschuldigungen einer verführten und von Bestechung berauschten Menge habe die siebzig Bischöfe in Karthago veranlasst, unschuldige und abwesende Kollegen $\mathrm{zu}$ verdammen. ${ }^{79}$ Und jene Bischöfe hätten in Rom noch einmal den Pöbel zum Ankläger Caecilians erheben wollen, doch die Richter dort nicht von ihrem Irrsinn überzeugen können. ${ }^{80}$ Die Richter in Rom nämlich hätten sich nicht von einer anonymen Masse beeinflussen lassen, sondern Ankläger, Zeugen und andere Beteiligte befragen wollen, die aus Afrika mitgereist waren. Doch Donatus, so werde gesagt, habe diese Zeugen entfernt und nicht mehr vorgeführt, obwohl er es versprochen habe. Donatus selbst habe schließlich verweigert, zu den Verhandlungen zu erscheinen, anscheinend um nicht in Gegenwart verurteilt zu werden. Allerdings sei in seiner Anwesenheit seine Schuld hinreichend erwiesen worden (43.15).

Zum Abschluss seiner Interpretation der römischen Akten geht Augustinus auf das Argument der donatistischen Ankläger ein, demgemäß die Anzahl von siebzig urteilenden Bischöfen in Karthago eine schwerwiegende Autorität darstelle, die nicht einfach zu ignorieren sei. Die Richter in Rom, erwidert $\mathrm{Au}$ gustinus, hätten die Anzahl der Bischöfe nicht mehr beachtet, als sie sahen, in welch blindem Eifer diese überstürzt, ohne Anhörung und in Abwesenheit der Beklagten, ihre Kollegen verurteilt hätten. Miltiades habe dagegen ein unbestechliches, vorsichtiges und friedfertiges Schlussurteil gesprochen. Er habe allein Donatus verurteilt, den er als Urheber des ganzen Übels ansah, allen anderen habe er die Möglichkeit zur Umkehr gegeben. Er habe die Bereitschaft

79 Vgl. Kriegbaum, Kirche der Traditoren, 107 mit Anm. 41 zum Verständnis von ep. 43.14. Eventuell beruft sich Augustinus hier auf spätere Zeugenaussagen.

80 Ep. 43.14: quali enim turbae illi consenserant [septuaginta episcopi], ut aduersus innocentes non interrogatos proferrent sententias, a tali turba etiam rursus accusari Caecilianum uolebant, sed plane non tales inuenerant iudices, quibus illam dementiam persuaderent. Ich lese 'non tales inuenerant iudices'. Die von Goldbacher bevorzugte Lesart 'tales' gibt im Zusammenhang keinen Sinn. 
erklärt, Gemeinschaftsbriefe an die von Maiorinus geweihten Bischöfe zu senden und bestimmt, dass dort, wo bereits zwei Bischöfe nebeneinander existierten, der früher Geweihte die Gemeinde behalten solle. Auf diese Weise habe der Frieden gesiegt:

„Vergleichet nun diese kleine Zahl von Bischöfen mit jener großen Menge, vergleichet aber nicht Zahl um Zahl, sondern das jeweilige Gewicht ihres Ansehens: Hier Besonnenheit, dort Unbesonnenheit, hier Wachsamkeit, dort Verblendung! Hier zerstörte weder die Milde die Gerechtigkeit, noch standen Gerechtigkeit und Milde im Widerspruch zueinander; dort aber wurde mit Zorn die Furcht überdeckt und durch die Furcht wurde der Zorn angespornt. Diese nämlich waren zusammengekommen, um durch die Untersuchung der wahren Verbrechen die falschen zurückzuweisen, jene aber, um durch Verdammung der falschen Verbrechen die wirklichen zu verbergen." ${ }^{81}$

Die Analyse der Konzilsakten ergänzt Augustinus durch zwei weitere Anschuldigungen gegen die bischöflichen Richter in Karthago, mit denen Caecilians Weigerung, vor diesem Gremium zu erscheinen, zusätzlich gerechtfertigt werden soll. Erstens gehe aus den gesta apud Zenophilum hervor, dass Secundus und die anderen Bischöfe nicht nur von ihrer eigenen Schuld ablenken wollten, sondern außerdem von der reichen Lucilla bestochen worden seien, jener Frau, die Caecilianus noch als Diakon beleidigt habe, als er sie kirchendisziplinarisch zurechtweisen musste. Zweitens habe bei einigen Bischöfen auch verletzte Eitelkeit dazu beigetragen, dass sie Caecilianus gegenüber feindlich eingestellt gewesen seien, da sie bei dessen Ordination nicht berücksichtigt worden seien. Diese Motive der Bischöfe hätten es Caecilianus unmöglich gemacht, sich dem Urteil in Karthago zu unterwerfen, da er schließlich keinen aufrichtigen Richtern, sondern feindlich gesinnten und bestochenen Leuten hätte entgegengetreten müssen. Gleichzeitig habe Caecilianus gewusst, dass von den überseeischen Bischöfen, abseits von Feindschaft und Parteilichkeit, eine gerechte Untersuchung zu erwarten sei, der sich auch seine Gegner unterziehen müssten, wenn sie sich nicht von der weltweiten Gemeinschaft trennen wollten. ${ }^{82}$

81 Ep. 43.16: conferte nunc istam paucitatem cum illa multitudine episcoporum neque numerum numero sed pondus ponderi comparate: hinc modestiam, inde temeritatem; hinc uigilantiam, inde caecitatem; hic nec mansuetudo integritatem corrupit nec integritas mansuetudine repugnauit, ibi autem et furore timor tegebatur et timore furor incibatur; isti enim conuenerant cognitione uerorum criminum falsa respuere, illi falsorum damnatione uera celare.

82 Ep. 43.17-18, vgl. 25-26. Zum Inhalt der gesta apud Zenophilum s. u. Kap. 6.2.2. - Zu Recht sieht Kriegbaum (Kirche der Traditoren, 110 Anm. 52) bei Augustinus eine vorgeschobene Begründung: Der Hauptgrund für Caecilians Weigerung, vor dem Konzil zu erscheinen, sei die Beeinträchtigung seiner Rechtsposition durch das Verlassen der Kathedra gewesen. Andernfalls hätte Caecilianus die fehlende rechtliche Bindung seiner Wahl zugegeben. 
Zusammenfassend ist festzustellen, dass Augustinus in der Gegenüberstellung der Konzile von Karthago und Rom das Verfahren in Karthago mit drei Argumenten angreift: Das erste Argument betrifft das Zustandekommen des römischen Konzils. Die Bitte um ein neues Bischofsgericht sei von den Donatisten ausgegangen und dieses Gericht sei in Rom rechtmäßig durchgeführt worden. Ein Widerspruch gegen die Richter daher nicht möglich. Mit seinem zweiten Argument stilisiert Augustinus den parteiischen karthagischen Pöbel zum eigentlichen Ankläger Caecilians. Dieser habe sich in Karthago Gehör verschaffen können, in Rom jedoch hätten andere Zeugen nichts mehr zu sagen gewusst. Die Gegenüberstellung der Richter von Karthago und der Richter von Rom verdeutlicht für Augustinus, wessen Urteil das rechtmäßige gewesen sei. Das dritte Argument spitzt den Gegensatz zwischen den Richtern noch weiter zu. Die Anzahl der Bischöfe sei nicht entscheidend, wenn elementare christliche Tugenden ignoriert und in Verblendung und Rachsucht Urteile gesprochen werden. Damit bleibt Augustinus auch hier im Bezug zum Konzil von Karthago: Die Leser sollen die Personen und die Urteile abwägen, nicht die Anzahl der Richter zählen. Zur Verstärkung zieht er die Bestechungsvorwürfe sowie das unchristliche Motiv der gekränkten Eitelkeit heran, um die Richter endgültig zu diskreditieren.

Augustins Interpretationen der römischen Akten und seine Ausführungen über Hintergründe und Motive der Donatisten sind eine wichtige Quelle für die Rekonstruktion dieser Ereignisse. Da die Protokolle der Verhandlungen in Rom nicht erhalten sind, wird zu fragen sein, wie seine Angaben in ep. $43 \mathrm{zu}$ bewerten sind. Auf jeden Fall ordnete er seine Informationen seiner Argumentationsstrategie unter, um die Differenz zwischen den Verhandlungen in Rom und Karthago herauszustellen. Rom sollte als Beispiel des richtigen und rechtmäßigen Umgangs mit kirchlichen Streitigkeiten dienen, als Wiedergutmachung der Versäumnisse in Karthago. ${ }^{83}$

Bevor Augustinus zum Abschluss der historischen Argumentation die endgültige Entscheidung der causa Caeciliani durch Konstantin referiert, ergänzt er einige Erklärungen zu dem Bittgesuch der Donatisten an Kaiser Konstantin. Es war ihm daran gelegen, einen drohenden Widerspruch auszuräumen, der sich durch seine vorangegangenen Ausführungen andeutete. Auf der einen Seite hatte er von der Notwendigkeit eines unabhängigen Gerichts in Übersee gesprochen, auf der anderen Seite die Durchführung des römischen Verfahrens mit der Initiative der Donatisten begründet. Augustinus musste also darlegen, warum die Klage der Donatisten beim Kaiser nicht der richtige Weg gewesen sei, und er führt dies aus, indem er die donatistischen Kläger wiederum einer falschen Motivation bezichtigt (43.18-19). Augustinus beanstandet, dass der 
Fall Caecilians nicht sofort vor ein europäisches Gericht getragen worden sei. Vermutlich hätten die Donatisten so lange gewartet, damit sich vor einem Prozess ihre falschen Gerüchte über die Zeit verfestigen konnten. Wahrscheinlicher sei jedoch, dass die Donatisten gar nicht gewagt hätten die Sache dort zu verhandeln, wo die Wahrheit ans Licht gekommen wäre, während sie sich in der Heimat im Vertrauen auf ihre Anzahl ihrer Sache völlig sicher gewesen seien (43.18). Die Donatisten hätten sich erst an ein Gericht in Übersee gewandt, als das Schisma schon längst vollzogen gewesen sei und sie gemerkt hätten, dass die Christenheit nicht mit ihnen, sondern mit Caecilianus Gemeinschaft halte. Da man den Donatisten hätte vorwerfen können, sie akzeptierten ohne Widerspruch die Gemeinschaft der anderen Kirchen mit dem von ihnen verurteilten Bischof, hätten sie handeln müssen.

Diese Ausführungen erwecken den Anschein, dass die Donatisten nicht aus Einsicht, sondern aus Notwendigkeit ein erneutes Bischofsgericht gefordert hätten. Nachdem die anderen Kirchen der Christenheit in der Gemeinschaft mit Caecilianus verblieben seien, mussten die Donatisten zur Überwindung der Isolation die Anerkennung aus Übersee erlangen, um nicht als Sekte angesehen zu werden. Das Bittgesuch an den Kaiser sei so zwingend geworden, um den donatistischen Bischof von Karthago als den rechtmäßigen bestätigen zu lassen. Augustinus kann auf diese Weise demonstrieren, dass zum einen die weltweite Kirche nicht zu missachten sei, zum anderen aber die donatistischen Ankläger Caecilians sich nicht aus Erkenntnis dieser Tatsache, sondern aus Zwang beugen mussten.

Anhand eines Konstantinbriefes, der während des Gesprächs auch vorgelesen wurde, stellt Augustinus dar, auf welche Weise aus seiner Sicht der Fall endgültig entschieden worden sei. In der Beschreibung der Prozessfolge gegen Caecilianus stellt Augustinus heraus, dass es für den Kaiser nicht nötig gewesen wäre, das Verfahren fortzusetzen, jedoch habe dieser der Hartnäckigkeit der Ankläger nachgegeben, in dem Wunsche, ihre Dreistigkeit zu bändigen. Er habe aber nicht gewagt, selbst über das Urteil der Bischöfe zu richten und habe deshalb ein weiteres Bischofsgericht eingesetzt. Für sein eigenes Urteil habe der Kaiser später die Bischöfe um Verzeihung gebeten. Doch die Donatisten hätten nicht so rücksichtsvoll gehandelt wie der Kaiser. Sie hätten weder dem Urteil der Bischöfe noch dem Urteil des Kaisers Folge geleistet, obwohl sie nichts mehr hätten vorbringen können. Folgendermaßen sei die Sache entschieden worden:

„Der Kaiser nämlich befahl, dass die beiden Parteien zu ihm nach Rom kommen sollen, um den Fall zu verhandeln. Weil aus mir nicht bekannten Gründen Caecilianus dort nicht eintraf, ordnete er auf ihren [der Donatisten] Einspruch an, dass sie [ihm] nach Mailand folgen sollten. Darauf begannen einige der [donatistischen Partei] sich heimlich aus dem Staub zu machen, vielleicht aus Empörung, weil Konstantin sie nicht nachahmte, indem er Caecilianus sofort und schnell in Ab- 
wesenheit aburteilte. Als der vorausschauende Kaiser dies bemerkte, ließ er die anderen unter Bewachung nach Mailand bringen. Nachdem auch Caecilianus dort angekommen war, ermittelte der Kaiser auch selbst, wie er schreibt, und nach Untersuchung des Falles - mit welcher Sorgfalt, Achtsamkeit und Weitsicht er vorging, beweist sein Brief - erklärte er Caecilianus für vollkommen unschuldig, seine Gegner aber umfassend für schuldig. “ 84

Augustinus gibt an dieser Stelle wichtige Informationen über den Abschluss der causa Caeciliani vor den bischöflichen Gerichten und durch das kaiserliche Urteil. Umso wichtiger ist es, genau zwischen Augustins Kenntnissen der Fakten und seinen Interpretationen zu unterscheiden. Die Fakten, von denen Augustinus ausging und die er dem angegebenen Kaiserbrief entnahm, sind schnell aufgeführt: Die Anklage der römischen Richter beim Kaiser, der Entschluss ein erneutes Urteil durch Bischöfe in Arles fällen zu lassen, der Appell der Donatisten nach Arles, die Entscheidung des Kaisers, selbst zu urteilen, die Vorladung der Parteien nach Rom, das Ausbleiben Caecilians, die Verlagerung des Hofes nach Mailand, der Fluchtversuch einiger Donatisten und schließlich die Verhandlungen in Mailand mit der Entscheidung zu Gunsten Caecilians. ${ }^{85}$

Augustinus ist sichtlich bemüht, den Brief in einer Weise zu interpretieren, die dem Kaiser eine weitgehend passive Rolle bei der Lösung des Streites beimisst. Konstantin erhält von Augustinus den Nimbus des christlichen Kaisers, der sich unermesslich großzügig gegenüber dem Begehren der Donatisten gezeigt habe und demütig gegenüber der katholischen Kirche und ihren Bischöfen. Als treibende Kraft beschuldigt Augustinus dagegen wiederum die Donatisten. Anders als bei ihrer ersten Bitte um Richter hebt er an dieser Stelle nicht nur die Initiative heraus, sondern unterstellt gleichzeitig eine Verletzung kirchlichen Rechts. Die Donatisten hätten die Bischöfe nicht beim Kaiser anklagen, sondern allenfalls ein weiteres Bischofsgericht anrufen dürfen! Die Einberufung des Konzils von Arles durch den Kaiser verteidigt Augustinus entsprechend: Der christliche Kaiser habe gleichsam die Anklage an ein rechtmäßiges Gremium zurückverwiesen und es so (in vorbildlicher Weise) unterlassen, als weltlicher Herrscher über Bischöfe zu urteilen. Die Zulassung der Revision selbst beurteilt Augustinus bereits als Zeichen von Großmütigkeit, keinesfalls

84 Ep. 43.20: iussit enim ille [imperator], ut ei partes ad agendam causam Romam occurrerent. quo cum Caecilianus nescio qua causa non occurrisset, interpellatus ab eis praecepit, ut Mediolanum sequerentur. tunc se aliqui eorum subtrahere coeperant fortasse indignati, quia non est eos imitatus Constantinus, ut iam statim atque uelociter Caecilianum damnaret absentem. quod ubi cognouit prouidus imperator, reliquos ab officialibus custoditos fecit Mediolanum peruenire. quo cum etiam Caecilianus uenisset, ipsum quoque, sicut scripsit, exhibuit, cognitaque causa qua diligentia. qua cautela, qua prouisione, sicut eius indicant litterae, Caecilianum innocentissimum, illos inprobissimos iudicauit.

85 Augustinus zitiert aus dem Brief Konstantins an den Vikar Eumalius. Zur Identifizierung vgl. unten Kap. 7.4. 
als Notwendigkeit. Damit stellt er das Urteil von Rom an den Platz, den die Donatisten dem Urteil von Karthago einräumten. Die Folgeurteile von Arles und schließlich des Kaisers gelten ihm somit als Bestätigungen des ersten und einzig rechtmäßigen Verfahrens im Fall Caecilianus: das Verfahren in Rom.

Den Prozess vor dem Kaiser kann und will Augustinus dennoch nicht umgehen. Immerhin bezeugte gerade das Urteil Konstantins nichts anderes, als die Bischöfe vorher bereits entschieden hatten. Wiederum rechtfertigt er jedoch das Handeln des Kaisers. Er weist auf die Worte Konstantins, mit denen dieser selbst die donatistischen Appelle kritisiert habe, und er lässt sich sogar zu der Aussage hinreißen, dass Konstantin die Bischöfe um Verzeihung gebeten habe, weil er das Verfahren übernommen hatte. Während die überlieferten Quellen die Kritik Konstantins an den Donatisten durchaus bestätigen, gibt es für einen irgendwie gearteten Bittgang des Kaisers vor die Bischöfe keinerlei Anhaltspunkte. Es passte aber Augustinus für den Augenblick der Überzeugungsarbeit in ep. 43 besser ins Bild, die Demut Konstantins in besonderer Weise herauszustellen. Über die weiteren Hintergründe der Verzögerung der Untersuchung und dem Ablauf in Mailand scheint Augustinus nicht im Detail unterrichtet gewesen zu sein. Über Caecilians Ausbleiben in Rom will er nicht spekulieren und für die vermeintlichen Fluchtversuche der Donatisten zieht er den Gegensatz von Anwesenheit und Abwesenheit vor Gericht heran, ohne jedoch den Hintergrund dieser seltsamen Flucht vom kaiserlichen Hof damit aufzuklären. Das Ziel Augustins war es, als Hinführung auf den Freispruch Caecilians durch Konstantin klarzustellen, dass der Kaiser weder aus eigener Anmaßung noch aus Parteilichkeit über Caecilianus entschieden habe, sondern einzig und allein, weil die Donatisten permanent auf sein Urteil gedrängt hätten, nachdem sie die kirchlichen Entscheidungsinstanzen nicht hätten anerkennen wollen. ${ }^{86}$

Ep. 43 ist ein Glücksfall in der Überlieferung. Welche Absicht Augustinus für die Zeit vor 405 mit der historischen Argumentation verfolgte, wird zwar auch in den kurzen Darstellungen von ep. 53 oder ep. 76 sowie in anderen Notizen zur causa Caeciliani deutlich, jedoch findet sich in keiner anderen Schrift dieses Zeitraums mehr über Augustins zielgerichtete Auslegung der historischen Dokumente. Augustinus arbeitete mit geschickten Gegenüberstellungen, juristischen Feinheiten und klaren Schuldzuweisungen, alles vorgetragen in glänzender Rhetorik. Mit seinen Interpretationen war er in der Lage, den Freispruch Caecilians in allen Facetten als rechtskräftig begreifbar zu machen. Augustinus widersprach vor allem den donatistischen Anklagen der Vermischung von Kirche und Staat, indem er deutlich das römische Urteil der Bischöfe in den Vordergrund rückte, während er das kaiserliche Urteil über Caecilianus, wie auch den Prozess gegen Felix von Abthugni, als von den Donatisten erzwungenen Zusatz darstellte. Nach Augustins Verständnis waren

86 Zur Einordnung von Augustins Ausführungen in den historischen Kontext s. u. Kap. 7.4. 
kirchenrechtlich die Urteile von Rom und Arles bindend, da nur dort dem geltenden Recht entsprechend verhandelt worden sei. Zum Nachweis der Rechtmäßigkeit verwies Augustinus auf die Anwesenheit des Angeklagten, die Unbestechlichkeit und Unabhängigkeit der bischöflichen Richter, die Anhörung beider Parteien mit aufrichtigen Zeugen sowie die Möglichkeit des Appells an ein Bischofsgericht in Übersee. Die Konsequenz aus dieser Darstellung sollten die Leser von ep. 43 ziehen: die Ungültigkeit des Urteils von Karthago 312 und dadurch der Verlust einer Legitimation der donatistischen Partei.

2.2 Kontinuität der Gesetzgebung: Die Briefe nach 405 (epp. 88, 89, 93, 105)

Die Veränderung in der Argumentation Augustins nach dem Unionsgesetz vom Februar 405 ist bei der Betrachtung der einzelnen Briefe bereits dargelegt worden. ${ }^{87}$ Es stellt sich hier die Frage, welche Auswirkungen die geänderten Voraussetzungen auf die Verwendung der historischen Argumente hatten. Die causa Caeciliani wird in den Briefen an Ianuarianus (ep. 88), an den Rogatisten Vincentius (ep. 93), an Festus (ep. 89) und an alle Donatisten (ep. 105) thematisiert. Augustinus beabsichtigte in allen vier Briefen mit seiner Interpretation des Falles Caecilianus einen Beweis für zwei Thesen zu führen:

Erstens, die Donatisten hätten als erste und ohne Zwang den Streitfall vor das kaiserliche Gericht getragen. Diese These ist bereits aus früheren Briefen und Schriften bekannt, wird nach 405 jedoch wesentlich stärker in den Vordergrund gerückt.

Zweitens, die neuen Gesetze gegen die Donatisten seien nichts anderes als die Erneuerung und konsequente Anwendung des längst von Konstantin gefällten Urteils im Fall Caecilianus. Augustinus versucht also, zwischen Vergangenheit und Gegenwart eine rechtliche Kontinuität herauszustellen. Derartige Bezüge auf bereits vorhandene, von früheren Kaisern verkündete Gesetze, die lediglich „erneuert“ werden, sind vielfach aus Gesetzestexten bekannt. Nicht zuletzt beruft sich Honorius in der Präambel des Unionsgesetzes von 405 selbst auf bereits bestehende Gesetze. Augustinus adaptiert insofern die juristischen Formulierungen und führt sie in seiner Argumentation weiter aus. ${ }^{88}$

Im Vergleich zu den Briefen vor 405 ist besonders auffällig, dass Ausführungen zur causa Silvani fehlen. Außer zwei kurzen Notizen zum Konzil von Karthago (ep. 88.3, 5) und Hinweisen, dass es Beweise für die Unwahrheit der traditio-Anklagen gebe (105.16-17), findet sich nichts zum Konzil von Cirta, Silvanus von Cirta oder über den Ablauf der Absetzung Caecilians in Karthago. Augustinus verzichtet somit auf die Erörterung der historischen traditio-Schuld

87 S. o. Kap. $4.1 .2-3$.

88 Vgl. o. Kap. 2.2.2. 
und damit auf die „Gegenklage“, die er unter anderem gegenüber Petilianus ausgiebig behandelte und später gegen Cresconius nochmals verteidigte. Er stellt die vor allem in ep. 43 intensiv betriebene Schuldzuweisung im Bezug auf die Urheber des Schismas in den Hintergrund und konzentriert sich auf die Urheberschaft der Klage gegen Caecilianus, den technischen Ablauf des Verfahrens und die juristischen Folgen.

Zum Beweis seiner ersten These konnte Augustinus auf ein Dokument zurückgreifen, das ihm vor 405 noch nicht zur Verfügung gestanden hatte: der Bericht des Prokonsuls Anullinus, mit dem dieser am 15. April 313 die von der pars Maiorini entgegengenommene Anklage an den Kaiser weitergeleitet hatte ${ }^{89}$ Während Augustinus in dreien der Briefe auf diese relatio Anullini lediglich hinweist, ${ }^{90}$ enthält der Brief an Ianuarianus den vollständigen Text des Dokuments. Darin berichtet Anullinus, dass er die kaiserliche Anordnung, Bischof Caecilianus und dessen Kleriker von Abgaben zu befreien, umgesetzt habe. Dann seien jedoch Gegner Caecilians, begleitet von einer Volksmenge, bei ihm erschienen. Diese hätten ihm zwei Schriftstücke (libelli) zur Weiterleitung an Konstantin übergeben, ein versiegeltes und ein offenes. Das versiegelte Schriftstück trug den Titel: „Libellus der katholischen Kirche bezüglich der Vergehen Caecilians überreicht von der Partei des Maiorinus“.91

Zweifellos musste jeder Leser dieses Dokuments, vorausgesetzt, er glaubte an seine Authentizität, Augustins Schlussfolgerung nachvollziehen, die er allen Adressaten gegenüber formuliert: Die Vorfahren der Donatisten seien zuerst den Weg zu den staatlichen Instanzen gegangen, indem sie Caecilianus durch Anullinus beim Kaiser angeklagt hätten. Augustinus hebt sehr deutlich die Freiwilligkeit dieser Anklage hervor, keiner habe damals die Donatisten gezwungen, den Kaiser anzurufen, sondern freiwillig, von sich aus (ultro) seien sie vor das Gericht gezogen. ${ }^{22}$

Auf dieser Feststellung baute Augustinus die weitere Argumentation zur Begründung seiner zweiten These auf - die Darstellung einer Kontinuität der Gesetzgebung: Mit der donatistischen Anklage seien die Verfahren erst ins Rollen gekommen. Dann habe der Kaiser aufgrund der Anklage zunächst das Bischofsgericht in Rom zusammengerufen, in dem die Sache entschieden und Caecilianus freigesprochen worden sei. Infolge der Appelle der Kläger an den Kaiser gegen dieses Urteil seien das zweite Bischofsgericht und schließlich das Verfahren vor dem Kaiser selbst notwendig geworden $(88.3 ; 89.3 ; 93.13 ; 105.8)$.

89 Dies hat Girardet (Chiron 19, 1989, 200-203) überzeugend nachgewiesen. Vgl. dazu unten Kap. 7.2.

90 Ep. 89.3; 93.13 (mit kurzem Zitat); 105.10.

91 Ep. 88.2; vgl. u. Kap. 7.2.

92 Ultro accusavit Caecilianum (88.1); ultro per Anulinum [...] accusare ausi sunt Caecilianum (89.3); ultro accusantes (93.14); causam Caeciliani ultro detulerunt (105.10). 
Allen Adressaten gegenüber kritisiert Augustinus, dass die Donatisten Caecilianus nicht vor anderen Bischöfen, sondern vor dem Kaiser verklagt hätten (88.5; 89.3; 93.13). In Gegenüberstellung zu diesem falschen Handeln lobt er den Kaiser. Konstantin habe es nicht gewagt, selbst über Bischöfe zu richten und deshalb den Fall an Bischöfe delegiert (105.8). Damit habe er wesentlich ordnungsgemäßer gehandelt (longe ordinatius agente) als die Ankläger selbst (93.13). Nur wegen der weiteren hartnäckigen Eingaben auch nach dem zweiten Bischofsurteil sei Konstantin gleichsam gezwungen worden, letztlich selbst in die kirchliche Angelegenheit (causa episcopalis) einzugreifen und zu entscheiden (88.3).

Indem er die Geduld des Kaisers, sein Zögern selbst zu urteilen und seine Unterordnung unter bischöfliche Entscheidungen hervorhob, versucht Augustinus, ein positives Herrschaftsbild zu vermitteln. Konstantin habe keineswegs unbedacht in die kirchliche Streitfrage eingegriffen oder sich gar bischöfliche Macht angemaßt, sondern er habe dem Druck der Donatisten am Ende nachgegeben. Deshalb laufe die donatistische Kritik an der kaiserlichen Unterstützung für die katholische Kirche ins Leere. So kann Augustinus an Vincentius gerichtet fragen: „Warum werft ihr uns vor, worauf eure Leute zuerst ihre Hoffnung gesetzt haben?"93

Während in den meisten Aufzählungen der donatistischen Appelle an Konstantin lediglich allgemein von einer Klage der Donatisten über das Urteil oder die urteilenden Bischöfe die Rede ist, wird im Brief an Ianuarianus eine kurze Begründung für die Berufung nach der Entscheidung von Rom genannt. Die Ankläger hätten vorgebracht, dass weder das Urteil rechtmäßig zustande gekommen noch der ganze Fall angehört worden sei (88.3: non recte iudicatum neque omnem causam auditam esse). ${ }^{94}$ Außerdem behaupten die Absender, nach dem Urteil der Bischöfe von Arles seien viele Anhänger der pars Donati zur Kirchengemeinschaft zurückgekehrt, ${ }^{95}$ einige andere aber im Schisma verblieben, die dann erneut appelliert hätten (88.3).

Entscheidend für Augustins Argumentation ist nun die Information über ein Gesetz gegen die Partei der Donatisten, das Konstantin nach seinem Urteil über Caecilianus erlassen haben soll. Dieses Gesetz, teilt Augustinus mit, habe im Falle von anhaltendem Widerstand gegen die Kircheneinheit, die Konfiszierung von Besitztümern verfügt. ${ }^{96}$ Für Augustins Argumentation setzt diese kaiserli-

93 Ep. 93.13: quid nobis obicitis, quod uestrorum praesumptio primitus fecit?

94 In Karthago 411 begründeten die Donatisten ihre Kritik am römischen Urteil wesentlich grundsätzlicher, als in ep. 88 dargestellt wird. Sie versuchten, Miltiades das traditioVergehen nachzuweisen. Vgl. u. Kap. 5.1.3.

95 Grasmück (Coercitio, 64) übernimmt diese Aussage unkritisch.

96 Ep. 88.3: [Constantinus] primus contra uestram partem legem constituit ut loca congregationum uestrarum fisco uindicarentur; 93.14: imperator primus constituit in hac causa, ut res conuictorum et unitati peruicaciter resistentium fisco uindicarentur. - Weniger 
che Verfügung den Ausgangspunkt für eine Verbindung zur aktuellen Lage: $:^{97}$ Nachdem die Entscheidung im Fall Caecilians gefallen sei, sei es dem Kaiser gar nicht mehr möglich gewesen, von dem einmal eingeschlagenen Weg abzuweichen. Dieses Gesetz sei die notwendige Folge aus dem Urteil zu Gunsten Caecilians gewesen. Im Falle eines anderen Ausgangs des Prozesses hätten ebenso entsprechende Maßnahmen gegen Caecilianus und seine Anhänger verhängt werden müssen $(89.5$; 93.14). Von diesen ersten gesetzlichen Bestimmungen gegen die Donatisten schlägt Augustinus den Bogen zu den Zwangsmaßnahmen seiner Zeit:

„Welches andere als jenes Urteil des älteren Konstantin gegen eure Partei lebt heute noch? Das Urteil, das eure Vorfahren wählten, das sie mit fortwährenden Beschwerden erpressten und das sie dem bischöflichen Urteil vorzogen. “"

Dieses selbst gewählte, ja Konstantin abgenötigte Urteil sei stets in Kraft gewesen, durchgehend anerkannt und von allen Kaisern mit Ausnahme Julians geachtet worden. Besonders anschaulich schildert Augustinus diese Kontinuität gegenüber den donatistischen Laien in ep. 105:

„Darauf erließ Konstantin zum ersten Mal ein sehr strenges Gesetz gegen die Partei des Donatus. Seine Söhne verfügten in gleicher Weise solche Gesetze. Ihnen folgte Julian, ein Apostat und Feind Christi, der auf Antrag eurer Vertreter Rogatianus und Pontius der Partei des Donatus eine Freiheit zum Verderben gewährte. Am Ende gab er den Häretikern die Basiliken zu dem Zeitpunkt zurück, als er den Dämonen die Tempel [zurückgab]. Er glaubte, auf diese Weise das Christentum von der Erde vertilgen zu können, wenn er die Einheit der Kirche, von der er abgefallen war, bekämpfte und den gottlosen Abspaltungen die Freiheit gestattete. Dies war seine zu preisende Gerechtigkeit, mit der die Bittsteller Rogatianus und Pontius den Apostaten lobten, indem sie sagten, bei ihm allein habe die Gerechtigkeit ihren Platz. Diesem folgte Jovian, der nichts in diesen Angelegenheiten verordnete, da er bald gestorben ist. Darauf kam Valentinian: Lest, was er gegen euch befahl! Dann Gratian und Theodosius: Lest, wenn ihr wollt, welche [Maßnahmen] sie gegen euch beschlossen. Warum wundert ihr euch also über die Söhne des Theodosius, als ob sie in dieser Sache etwas anderem folgen sollten, als

formal in 105.9: tunc Constantinus prior contra partem Donati seuerissimam legem dedit. - Anspielungen auf dieses Gesetz finden sich ausschließlich bei Augustinus: vgl. auch c. litt. Pet. II 205; c. ep. Parm. I 13, 18. Aus einem Reskript des Jahres 321 an den Vikar Verinus (breuic. III 40, 42) lässt sich schließen, dass es zuvor Verbannungen von Bischöfen gegeben hatte. Wahrscheinlich gehen diese Maßnahmen auf das von Augustinus erwähnte Gesetz zurück; vgl. u. Kap. 6.3.1. Vgl. Grasmück (Coercitio, 84), der ohne nähere Begründung meint, dass sich CTh XVI 6.2 auf die bei Augustinus erwähnte lex beziehe.

97 Monceaux (VI, 295) stellt nur eine Absicht der Absender heraus, die Initiative der Donatisten beim Kaiser. Er übersieht die konkrete Anknüpfung an die Kontinuität der Gesetzgebung.

98 Ep. 88.5: et nunc quid aliud quam ipsius maioris Constantini iudicium contra uestram partem uiuit, quod maiores uestri elegerunt, quod assiduis interpellationibus extorserunt, quod episcopali iudicio praetulerunt? 
dem Urteil Konstantins, das von so vielen christlichen Kaisern strengstens beibehalten wurde?“99

Augustinus nennt die geschlossene Kette der Kaiser bis hin zu Honorius und Arcadius, die mit Ausnahme des von den Donatisten hofierten Julian den Verordnungen Konstantins gefolgt seien. Mit einem Satz fasst er nochmals zusammen: „Konstantin ist tot, aber das Urteil Konstantins gegen euch lebt."

Augustinus ließ keine Möglichkeit aus, um seine These noch weiter zu untermauern. An der zitierten Stelle wie auch gegenüber Vincentius (93.12) stellt Augustinus Kaiser Julian heraus und präsentiert ihn gleichsam als Antitypus zu Konstantin. Ausgerechnet an den Herrscher, der als einziger mit den Verordnungen des christlichen Kaisers Konstantin gebrochen hatte, hätten sich die Donatisten mit der Bitte um Hilfe gewandt und ihn anschließend für seine Unterstützung auch noch belobigt. Allein wegen dieses Handelns könne jeder Vorwurf gegen katholische Bitten an christliche Kaiser ad absurdum geführt werden. Auch die von ihm häufig herangezogene Gewalt der Donatisten gegen die Maximianisten verwendet Augustinus für den Nachweis gesetzlicher Kontinuität. Schließlich seien die Donatisten auf Grundlage der bestehenden und damit gültigen Gesetze gegen die Maximianisten und andere Abspaltungen vorgegangen $(88.11$; 93.12). Gegenüber Vincentius bezieht Augustinus bisher geschehene Konversionen ebenfalls auf die bereits seit Konstantin bestehende Gesetzgebung. Durch diese Gesetze seien die Donatisten aus ihrer Erstarrung, Trägheit oder ihrem Hochmut gerissen und auf den richtigen Weg aufmerksam worden (93.17). ${ }^{101}$

99 Ep. 105.9: Tunc Constantinus prior contra partem Donati seuerissimam legem dedit. hunc imitati filii eius talia praeceperunt. quibus succedens Iulianus, desertor Christi et inimicus, supplicantibus uestris Rogatiano et Pontio libertatem perditioni parti Donati permisit; denique tunc reddidit basilicas haereticis, quando templa daemoniis. eo modo putans Christianum nomen posse perire de terris, si unitati ecclesiae, de qua lapsus fuerat, inuideret et sacrilegas dissensiones liberas esse permitteret. haec erat eius praedicanda iustitia, quam supplicantes Rogatianus et Pontius laudauerunt dicentes homini apostatae, quod apud eum sola iustitia haberet locum. huic successit Iovianus, qui quoniam cito mortuus est, nihil de rebus talibus iussit. deinde Valentianus; legite, quae contra uos iusserit. inde Gratianus et Theodosius; legite, quando uultis, quae de uobis constituerint. quid ergo de filiis Theodosii miramini, quasi aliud in hac causa sequi debuerunt, quam Constantini iudicium per tot Christianos imperatores firmissime custoditum? - $\mathrm{Zu}$ den donatistischen Legaten Rogatianus und Pontius vgl. Opt. II 16; c. litt. Pet. II 184, 205, 224; Maier II, Nr. 39, 42 f.; Congar, BA 28, 730 f.; Quinot, BA 30, 797-799; Mandouze, PAC, 986, s. v. Rogatianus 5; 885 f., s. v. Pontius 1.

100 Ep. 105.10: defunctus est Constantinus, sed iudicium Constantini contra uos uiuit.

101 Die alttestamentliche Danielerzählung (Dan. 6.16-24) verwendet Augustinus als biblisches Vorbild gesetzlicher Konsequenz: Daniel wurde als Opfer einer falschen Anklage den Löwen vorgeworfen. Nachdem die Verlogenheit der Ankläger ans Licht gekommen war, wurden diese zu der gleichen Strafe verurteilt, die sie Daniel zugedacht hatten. Augustinus folgert daraus: „In gleicher Weise warfen eure Vorfahren Caecili- 
Während Augustinus gegenüber den donatistischen Adressaten die Sinnlosigkeit eines Aufbegehrens gegen die bestehenden Gesetze postuliert, da sie selbst von ihnen herausgefordert worden seien, so erläutert er mithilfe der gleichen Argumente gegenüber dem Katholiken und Beamten Festus, warum die Donatisten im Unrecht seien und bekämpft werden müssten. Festus sollte erkennen, dass die gegenwärtigen Maßnahmen gegen die Donatisten keine ungerechte Verfolgung seien, sondern nichts anderes als eine zwangsläufige Sanktion für den Verstoß gegen eine kaiserliche Verfügung. Diese Verfügung sei am Ende eines rechtmäßigen Verfahrens ergangen, nachdem dieses Verfahren auf juristisch korrektem Weg von den Donatisten selbst eingebracht worden sei. Die donatistische Haltung, sich selbst als Opfer der Verfolgung und als Märtyrer $\mathrm{zu}$ stilisieren, entbehre insofern jeglicher Grundlage. ${ }^{102} \mathrm{Im}$ Gegensatz dazu präsentiert Augustinus die katholische Seite als gesetzestreu und dem Willen

anus und seine Anhänger dem königlichen Zorn zum Verzehr vor. Nachdem dieser von den Königen wegen seiner Unschuld befreit worden war, erleidet ihr nun das, was eure Leute diesen antun wollten. Wie geschrieben steht: Wer dem nächsten eine Grube gräbt, wird selbst in sie hereinfallen." (similiter maiores uestri Caecilianum et eius societatem regiae irae consumendam obiecerunt, cuius innocentia liberata ab eisdem regibus eadem uos patimini, quae illos uestri pati uoluerunt, quoniam scriptum est: Qui parat proximo foueam, ipse incidet in eam [Eccl. 27, 29]), ep. 88.5; vgl. ep. 93.19.

102 Ep. 89. 3: „Wenn nämlich Caecilianus und seine Kollegen, nachdem sie von jenen angeklagt und besiegt worden wären, von ihren jeweiligen Bischofsitzen herunter gestoßen oder gar wegen Verbleibens in ihrer Verschwörung noch härter bestraft worden wären (die königliche Aufsicht konnte schließlich nicht hinnehmen, dass Besiegte auch noch Widerstand leisten), dann hätten sie sich dazu aufgeschwungen, in Lobeshymnen die Voraussicht und gewissenhafte Sorge [des Kaisers] für die Kirche zu verkünden. Nun aber, weil sie besiegt worden sind, da sie gegen jene, die sie zu richten suchten am wenigsten etwas beweisen konnten, nennen sie es Verfolgung, wenn sie irgendetwas für ihr Unrecht erleiden. Und sie halten ihre so große verderbliche Raserei kaum zurück, sondern suchen sogar die Ehre der Märtyrer, als ob gegen ihr so hartnäckiges Unrecht die wahren christlichen katholischen Kaiser irgendetwas anderes befolgen würden als das Urteil Konstantins, bei dem sie freiwillig Caecilians Ankläger waren und dessen Autorität sie allen Bischöfen in Übersee vorzogen, so dass sie eine Angelegenheit der Kirchen nicht [den Bischöfen], sondern [dem Kaiser] übertrugen und von diesem ein Bischofsgericht in der Stadt Rom bestellt wurde, vor dem sie zuerst besiegt wurden." (sed uidelicet si eis accusantibus atque superantibus Caecilianus eiusque collegae pellerentur sedibus, quas tenebant, uel etiam in sua conspiratione durantes grauius punirentur - neque enim poterat uictos et resistentes regia censura contemnere - tunc isti prouisionem suam et pro ecclesia sollicitam curam praedicandam laudibus uentilarent. nunc autem quia ipsi superati sunt, qui ea, quae intendebant, probare minime potuerunt, si quid pro sua iniquitate patiuntur, persecutionem uocant; nec tantum furorem perditum minime reprimunt, uerum etiam honorem martyrum quaerunt, quasi uero Christiani catholici imperatores aduersus eorum pertinacissimam iniquitatem aliud sequantur quam Constantini iudicium, apud quem ultro Caeciliani accusatores fuerunt, cuius auctoritatem omnibus transmarinis episcopis praetulerunt, ut non ad illos sed ad illum ecclesiae causam deferrent, ut ab eo datum in urbe Roma episcopale iudicium, in quo primum uiciti sunt, [...]). 
des Kaisers ergeben. Nach der Anklage beim Prokonsul sei den Anhängern Caecilians nichts anderes übrig geblieben, als dem Urteil zu gehorchen, und auch die gesamte Christenheit sei auf das Urteil der Richter angewiesen. Wenn man auch sagen könne, dass ein menschliches Urteil durch Einschmeichelung, Täuschung oder Bestechung beeinflusst werde, letztlich seien die Richter Gott verantwortlich und der Unwissende müsse denjenigen vertrauen, die das Urteil gesprochen haben (89.4). Diesem Urteil, so die Erwartung Augustins, solle sich auch Festus beugen und zur Umsetzung der Sanktionen beitragen.

Die Erörterung des Falles Felix von Abthugni war für die Darstellung der gesetzlichen Kontinuität entbehrlich. Dies dürfte der Grund sein, warum Augustinus gegenüber Festus und Vincentius auf eine Darlegung dieses Falls verzichtete. Dennoch kommt er in epp. 88 und 105 auf die causa Felicis zu sprechen, wobei nicht mehr die Frage im Zentrum steht, ob Felix der traditio schuldig gewesen sei oder nicht, sondern der Verfahrensablauf. So wird die causa Felicis zum zusätzlichen Argument für Augustins erste These: Gegen Felix sei wie bei Caecilianus aufgrund andauernder Beschwerden der Donatisten auf Befehl des Kaisers die Untersuchung durchgeführt worden, die mit dem Freispruch durch den Prokonsul Aelianus abgeschlossen worden sei $(88.3 ; 105.8,10)$. Augustinus hebt mit dieser Ergänzung die Erfolglosigkeit sämtlicher Beschwerden und Anklagen der donatistischen Partei und die Eindeutigkeit der kaiserlichen Urteile hervor. Die Betonung liegt wiederum auf der Initiative der Donatisten: Für das Verfahren gegen Felix seien sie ebenso verantwortlich wie für das Verfahren gegen Caecilianus.

In ep. 88 an Ianuarianus erhält die causa Felicis eine weitaus bedeutendere Funktion. So wie der eingefügte Anullinusbericht die Anklageinitiative der Donatisten gegen Caecilianus beweisen sollte, so sollte der vollständige Text des Briefes Konstantins an den Prokonsul Probianus Gleiches für den Prozess gegen Felix erweisen. ${ }^{103}$ Auf den ersten Blick scheint es eine gewichtige Stütze der Argumentation zu sein, dass dieses Dokument zitiert wird. Auf den zweiten Blick lässt sich erkennen, dass Augustins Interpretation der Aussagen Konstantins überzogen ist. Denn von einer donatistischen Anklage gegen Felix oder einem Drängen zu einem Urteil ist in diesem Brief explizit nicht die Rede. Es heißt lediglich, dass der damalige Prokonsul Aelianus in Vertretung des erkrankten Vikars Verus geglaubt habe, die Untersuchung im Fall Caecilianus an sich ziehen zu müssen und daraufhin die Anhörung bezüglich Felix von Abthugni durchgeführt habe. Zweifellos konnte Augustinus bei Optatus von Mileve lesen, dass der Auftrag zum Verfahren gegen Felix, durch donatistische Eingaben veranlasst, vom Kaiser erteilt worden sei, ${ }^{104}$ und Augustinus ging offensichtlich von dieser Darstellung aus. Jedoch war der herangezogene Brief an

103 Der Text des Briefes in ep. 88.4. Zum Inhalt vgl. auch o. Kap. 3.4.2.2.

104 Opt. I 27. 
Probianus kein Beweis für ein Verfahren in dieser Abfolge. Der Versuch war somit misslungen, Ianuarianus mithilfe dieses Briefes neben dem Bericht des Anullinus ein weiteres Zeugnis für eine donatistische Initiative beim Kaiser zu liefern. ${ }^{105}$

105 Der Brief an Probianus beinhaltet allerdings andere Aussagen, mit denen die Donatisten kaum weniger in ein schlechtes Licht gerückt wurden: Der Misserfolg ihrer traditio-Anschuldigungen gegen Felix wird ebenso deutlich wie Konstantins Beschwerde über die tagtäglichen Appelle der Donatisten (88.4). Doch diese Aspekte lassen die Absender beiseite. Entscheidend für ihre Intention ist allein der Nachweis, dass in allen Anklagen und Prozessen die Vorfahren der Donatisten die treibende Kraft gewesen seien. - Bezeichnenderweise präsentierten auf der Konferenz von 411 nicht die Katholiken, sondern die Donatisten diesen Brief als Beweisstück für ihre Geschichtsdarstellung! Vgl. u. Kap. 5.1.3 und 6.1.3. 